San Jose State University

SJSU ScholarWorks

Master's Theses

Master's Theses and Graduate Research

Spring 2016

\title{
Simulating and Understanding a Summertime Dry Lightning Event in Coastal California
}

Philip Isaac Martin

San Jose State University

Follow this and additional works at: https://scholarworks.sjsu.edu/etd_theses

\section{Recommended Citation}

Martin, Philip Isaac, "Simulating and Understanding a Summertime Dry Lightning Event in Coastal California" (2016). Master's Theses. 4697.

DOI: https://doi.org/10.31979/etd.65y3-dgka

https://scholarworks.sjsu.edu/etd_theses/4697

This Thesis is brought to you for free and open access by the Master's Theses and Graduate Research at SJSU ScholarWorks. It has been accepted for inclusion in Master's Theses by an authorized administrator of SJSU ScholarWorks. For more information, please contact scholarworks@sjsu.edu. 


\title{
A SUMMERTIME DRY LIGHTNING EVENT IN COASTAL CALIFORNIA
}

\author{
A Thesis \\ Presented to \\ The Faculty of the Department of Meteorology and Climate Science \\ San José State University \\ In Partial Fulfillment \\ of the Requirements for the Degree \\ Master of Science
}

by

Philip I. Martin

May 2016 
(C) 2016

Philip I. Martin

ALL RIGHTS RESERVED 
The Designated Thesis Committee Approves the Thesis Titled

SIMULATING AND UNDERSTANDING

A SUMMERTIME DRY LIGHTNING EVENT IN COASTAL CALIFORNIA

by

Philip I. Martin

\section{APPROVED FOR THE DEPARTMENT OF METEOROLOGY AND CLIMATE SCIENCE}

\section{SAN JOSÉ STATE UNIVERSITY}

MAY 2016

Dr. Alison F. C. Bridger Department of Meteorology and Climate Science

Dr. Martin Leach Department of Meteorology and Climate Science

Dr. Sen Chiao Department of Meteorology and Climate Science 


\section{ABSTRACT \\ SIMULATING AND UNDERSTANDING \\ A SUMMERTIME DRY LIGHTNING EVENT IN COASTAL CALIFORNIA}

by Philip I. Martin

Thunderstorms are rare in coastal California during the summer months. Synoptic situations that encourage these summertime thunderstorms typically involve elevated instability that promotes dry lightning thunderstorms, where less than 0.1 in of precipitation reaches the ground. On 21 June 2008, a poorly forecasted dry lightning outbreak was responsible for starting more than 1,500 wildfires across California, and specifically the Monterey region. In this research, we used analysis data from the Global Forecast System (GFS) model to investigate the evolution of the synoptic conditions leading up to the outbreak. We then created two sets of ensembles with the Weather Research and Forecasting (WRF) mesoscale model to determine if dry convection could be simulated in areas where lightning strikes were observed. Two of the WRF-NAM ensemble members showed skill in simulating the Monterey convection. Instability and moisture fields in these simulations were also indicative of dry convection. Graupel behavior was analyzed in these simulations to determine lightning potential following McCaul et al. (2009). Overall, the convection generated by these simulations was found to be robust enough for modest cloud electrification, but recalibration that includes dry convection may be necessary to further improve this method of lightning threat detection. 


\section{ACKNOWLEDGEMENTS}

From unknown programming errors to weddings and camping trips, my graduate career has had its ups and downs, but the wonderful folks in the Department of Meteorology and Climate Science at SJSU made it worth the while. First, I would like to thank my mentor and advisor, Dr. Alison F. C. Bridger for guiding me through this incredible journey. Dr. Bridger helped to foster perseverance and curiosity by assuring me that sometimes it is okay to not know the answer. She is the original Ms. Frizzle, always encouraging me to dive in and "get messy." I would also like to thank the other members of my committee - Dr.

Sen Chiao and Dr. Marty Leach. Your feedback and support were instrumental in the success of my endeavors. Thanks are also due to Dr. Warren Blier at the NWS office in Monterey, whose correspondence greatly helped in my understanding of dry lightning.

Many thanks go to the great friends I have made in the Meteorology department. I was a silly southern boy from North Carolina, but you welcomed me with open arms. Special thanks go to Chrissy Williams, Diana Centeno, Shirin Zarrinkamar, Liz Chinoranski, and Kelly McDonnell among others for always having the time of day for me and encouraging me along the way.

Finally, I would like to thank my friends, family, and especially my parents, Bryan and Jenny Martin, for always telling me that I am their super star. Most of all, I would like to thank my sun and stars - my wonderful husband, Tommy. 


\section{TABLE OF CONTENTS}

List of Tables .......................................................................................

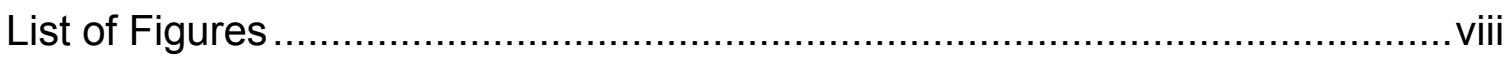

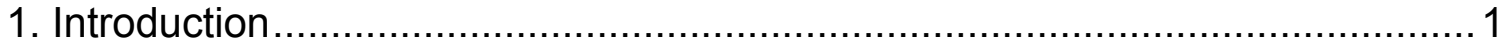

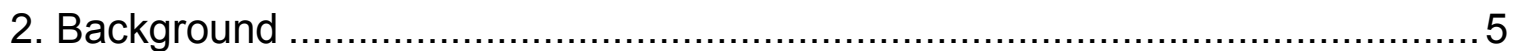

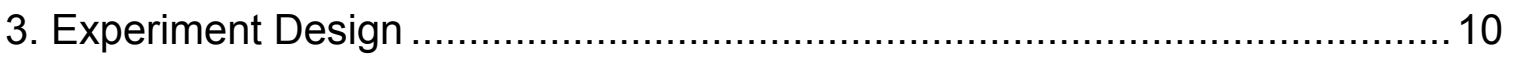

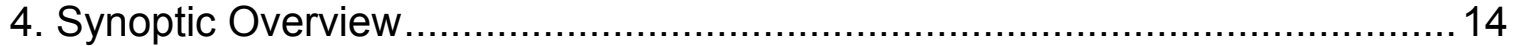

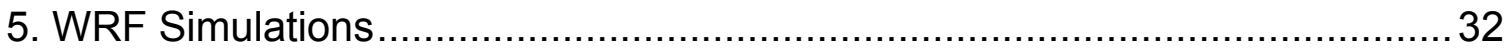

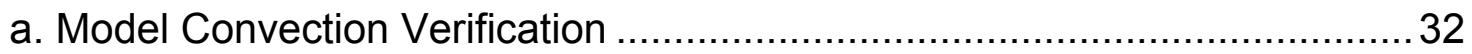

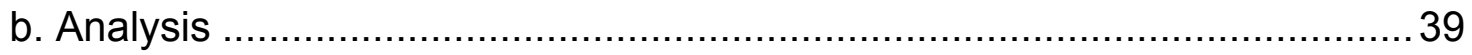

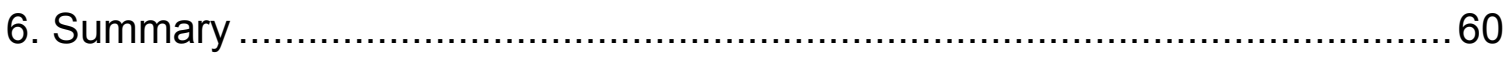

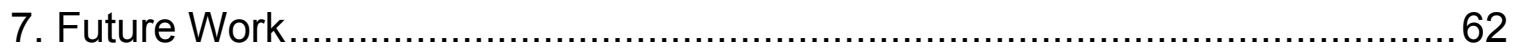

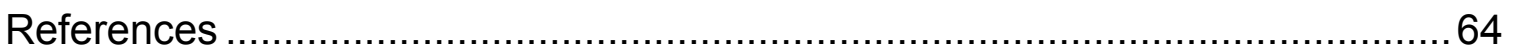




\section{LIST OF TABLES}

Table 1: GFS Analysis data in relation to 21 June 2008 at 1800 UTC ...............11

Table 2: WRF-GFS members and relation to 21 June 2008 at 1800 UTC .......... 12

Table 3: WRF-NAM members and relation to 21 June 2008 at 1800 UTC .........12 


\section{LIST OF FIGURES}

Fig. 1: Purple and red flame symbols indicate new and ongoing fires or complexes as of 0800 UTC on 23 June 2008 (Courtesy of the California Office of Emergency Services). [Available online at http://www.fire.ca.gov/about/downloads/Statewide_Fire_Maps/ StatewideFireMap_062308.pdf]........................................................ 2

Fig. 2: Monthly observed precipitation (in) for June 2008. [Available at http://water.weather.gov/precip/]

Fig. 3: This plot shows the location and timing of all lightning strikes on 21 June 2008. Storms came ashore on the northern coastal counties of California around and just after midnight local time (0700 UTC). Storms in the Monterey Bay region appeared around 11:00 am local time (1800 UTC) and continued onshore and inland into the afternoon.

Fig. 4: Evolution of the $500 \mathrm{hPa}$ geopotential heights (contours, GPM) and absolute vorticity (filled, $\mathrm{s}^{-1}$ ) from GFS analysis data (0-hour forecast). Here, $T=0$ is representative of the convection outbreak in the Monterey Bay, 1800 UTC on 21 June 2008.

Fig. 5: Evolution of the $500 \mathrm{hPa}$ temperature (filled, $\mathrm{K}$ ) and winds (vectors) from GFS analysis data (0-hour forecast). Here, $T=0$ is representative of the convection outbreak in the Monterey Bay, 1800 UTC on 21 June 2008.

Fig. 6: Evolution of the $700 \mathrm{hPa}$ geopotential heights (contours, GPM) and absolute vorticity (filled, $\mathrm{s}^{-1}$ ) from GFS analysis data (0-hour forecast). Here, $T=0$ is representative of the convection outbreak in the Monterey Bay, 1800 UTC on 21 June 2008.

Fig. 7: Evolution of the $700 \mathrm{hPa}$ temperature (filled, K) and winds (vectors) from GFS analysis data (0-hour forecast). Here, $T=0$ is representative of the convection outbreak in the Monterey Bay, 1800 UTC on 21 June 2008.

Fig. 8: Evolution of the $925 \mathrm{hPa}$ geopotential heights (contours, GPM) and absolute vorticity (filled, $\mathrm{s}^{-1}$ ) from GFS analysis data (0-hour forecast). Here, $T=0$ is representative of the convection outbreak in the Monterey Bay, 1800 UTC on 21 June 2008. 
Fig. 9: Evolution of the $925 \mathrm{hPa}$ temperature (filled, $\mathrm{K}$ ) and winds (vectors) from GFS analysis data (0-hour forecast). Here, $T=0$ is representative of the convection outbreak in the Monterey Bay, 1800 UTC on 21 June 2008.

Fig. 10: $2 \mathrm{PVU}$ pressure $(\mathrm{hPa})$ with wind barbs at the $2 \mathrm{PVU}$ level from GFS analysis data (0-hour forecast) valid 19 June 2008 at $0000 Z$.

Fig. 11: $2 \mathrm{PVU}$ pressure $(\mathrm{hPa})$ with wind barbs at the $2 \mathrm{PVU}$ level from GFS analysis data (0-hour forecast) valid 21 June at $0600 Z$.

Fig. 12: Evolution of geopotential height at $700 \mathrm{hPa}$ (contour, GPM) and Q-Vector divergence (fill) with T=0 set to June 21, 2008 @ $18 Z$. Red colors indicate forcing for descent (negative omega) and blue colors indicate forcing for ascent (positive omega).

Fig. 13: Wind streamlines at $700 \mathrm{hPa}$ from GFS analysis data (0-hour forecast) for 20 June 2008 at $0600 Z$. Red line indicates transect line for Figure 14. Green shading indicates water vapor mixing ratios greater than $5 \mathrm{~g} \mathrm{~kg}^{-1}$ at $650 \mathrm{hPa}$.

Fig. 14: Vertical cross-section of water vapor mixing ratio $\left(\mathrm{g} \mathrm{kg}^{-1}\right)$ from GFS analysis data (0- hour forecast) valid at 1200 UTC on a) 18 June 2008, b) 19 June 2008, c) 20 June 2008, and d) 21 June 2008 along transect from Figure 13.

Fig. 15: Evolution of geopotential height (contour, GPM) and wind speed (fill, $\mathrm{mph}$ ) at the $250 \mathrm{hPa}$ level from GFS analysis data (0-hour forecast) with $\mathrm{T}=0$ set to 21 June 2008 at 1800 UTC.

Fig. 16: Maximum simulated column cloud fraction in the WRF-GFS hindcasts valid 21 June 2008 at 1900 UTC. Red tick marks indicate observed lightning strikes between 1800 - 1900 UTC.

Fig. 17: Maximum simulated column cloud fraction in the WRF-NAM hindcasts valid 21 June 2008 at 1900 UTC. Red tick marks indicate observed lightning strikes between 1800 - 1900 UTC.

Fig. 18: Maximum simulated reflectivity ( $\mathrm{mdBZ}$ ) in WRF-GFS hindcasts valid 21 June 2008 at 1900 UTC. Red tick marks indicate lightning strike observations from $1800-1900$ UTC. 
Fig. 19: Maximum simulated reflectivity (mdBZ) in WRF-NAM hindcasts valid 21 June 2008 at 1900 UTC. Red tick marks indicate lightning strike observations from $1800-1900$ UTC.

Fig. 20: Temperature and dew point temperature profiles from WRF-NAM simulations (dashed) compared with OAK sounding (solid) valid 21 June 2008 at 0000 UTC. N5 had not yet been initiated at this time.

Fig. 21: Temperature and dew point temperature profiles from WRF-NAM simulations (dashed) compared with OAK sounding (solid) valid 21 June 2008 at 1200 UTC.

Fig. 22: Simulated vapor mixing ratio $\left(\mathrm{g} \mathrm{kg}^{-1}\right)$ profile from a point roughly $125 \mathrm{~km}$ offshore from Monterey $\left(36^{\circ} \mathrm{N}, 123^{\circ} \mathrm{W}\right)$ from WRF-NAM simulations valid 21 June 2008 at 1800 UTC, in the region where lightning strikes were observed. Bold lines indicate WRF-NAM simulations that generated convection near Monterey.

Fig. 23: Simulated CAPE $\left(\mathrm{J} \mathrm{kg}^{-1}\right)$ along the $16^{\text {th }}$ vertical level from WRFNAM hindcasts valid 21 June 2008 at 1800 UTC. This vertical level corresponds roughly to the $650 \mathrm{hPa}$ level in the model. Red line indicates transect location for Figure 24.

Fig. 24: Vertical cross-sections from WRF-NAM hindcasts of simulated CAPE (black contours, $\mathrm{J} \mathrm{kg}^{-1}$ ) and vapor mixing ratio (color fill, $\mathrm{g} \mathrm{kg}^{-}$ ${ }^{1}$ ) valid 21 June 2008 at 1800 UTC. Crosshatch indicates CAPE values that exceed $200 \mathrm{~J} \mathrm{~kg}^{-1}$. Transect location is indicated by red lines in Figure 23.

Fig. 25: Simulated upper level lapse rates $\left(T_{500}-T_{300},{ }^{\circ} \mathrm{C} \mathrm{km}^{-1}\right)$ from WRF-NAM hindcasts valid 21 June 2001 at 1800 UTC. Dashed line indicates the $7.5^{\circ} \mathrm{C} \mathrm{km}^{-1}$ threshold found to be useful in forecasting dry lightning, according to Nauslar et al. (2013). Red lines indicate transect locations for Figures 26-29.

Fig. 26: Vertical cross-sections from WRF-NAM hindcasts of simulated relative humidity (contour, \%) and vertical velocity (fill, $\mathrm{cm} \mathrm{s}^{-1}$ ) valid 21 June 2008 at 1800 UTC. Red shading indicates upward vertical motion and blue shading indicates downward vertical motion.

Fig. 27: Vertical cross-sections from WRF-NAM hindcasts of simulated relative humidity (contour, \%) and vertical velocity (fill, $\mathrm{cm} \mathrm{s}^{-1}$ ) valid 21 June 2008 at 1900 UTC. Red shading indicates upward vertical motion and blue shading indicates downward vertical motion. 
Fig. 28: Vertical cross-sections from WRF-NAM N3 (top) and N5 (bottom) simulations of positive vertical velocity (contour lines, $\mathrm{cm} \mathrm{s}^{-1}$ ) and graupel mixing ratio (color fill, $\mathrm{g} \mathrm{kg}^{-1}$ ) valid 21 June 2008 at 1800 UTC. The single dashed line is the $-15^{\circ} \mathrm{C}$ isotherm and the single bold line is the $0{ }^{\circ} \mathrm{C}$ isotherm.

Fig. 29: Vertical cross-sections from WRF-NAM N3 (top) and N5 (bottom) simulations of positive vertical velocity (contour lines, $\mathrm{cm} \mathrm{s}^{-1}$ ) and graupel mixing ratio (color fill, $\mathrm{g} \mathrm{kg}^{-1}$ ) valid 21 June 2008 at 1900 UTC. The single dashed line is the $-15^{\circ} \mathrm{C}$ isotherm and the single bold line is the $0{ }^{\circ} \mathrm{C}$ isotherm.

Fig. 30: Hindcast N3 simulated vertical graupel flux through the $-15^{\circ} \mathrm{C}$ isotherm (top, color fill) and zoomed in around the Monterey convective bands (bottom) to show relative size of elements in comparison to individual grid cells, valid 21 June 2008 at 1845 UTC.

Fig. 31: Hindcast N5 simulated vertical graupel flux through the $-15^{\circ} \mathrm{C}$ isotherm (top, color fill) and zoomed in around the Monterey convective bands (bottom) to show relative size of elements in comparison to individual grid cells, valid 21 June 2008 at 1845 UTC 


\section{Introduction}

On 21 June 2008, a storm system impacted the Pacific Northwest region of the US. This system spawned many dry lightning thunderstorms that caused over 1,500 individual wildfires in central and northern California. These dry lightning thunderstorms produced less than 0.1 inches of rainfall in conjunction with cloud-to-ground lightning strikes. Despite initial suppression efforts from firefighters, many larger complexes continued to burn for days and weeks after the storm had passed (Figure 1). A dry-season heat wave that preceded the storm made conditions more dangerous and favorable for expansive wildfire growth. Figure 2 shows that little to no precipitation was observed across the majority of California for the month of June 2008 , and supports the idea that vegetation was likely stressed at the time of the lightning outbreak.

Forecast discussions leading up to the outbreak tended to focus on the effects of the approaching short wave trough on the northern California region. Model guidance suggested that there would not be sufficient instability available at the surface to generate the convection that was actually observed in the early afternoon hours near the Monterey Bay. Lightning data provided by SUNY Albany indicated in fact that the convection first formed over the ocean and was robust enough to last several hours after coming on shore (Figure 3).

There are three main goals for this research. The first is to assess our current understanding of synoptic scale features that contribute to dry lightning convection and determine if there were any missing elements in forecasts for this 
event. The second goal is to simulate the outbreak with a mesoscale numerical model to determine if solutions suggest convection in the region where lightning was observed and, if so, identify the factors with the most influence on convective initiation. The last goal is to determine if lightning threat can be assessed from numerical simulations, and if these applications are suitable in conditions where dry lightning outbreaks occur.

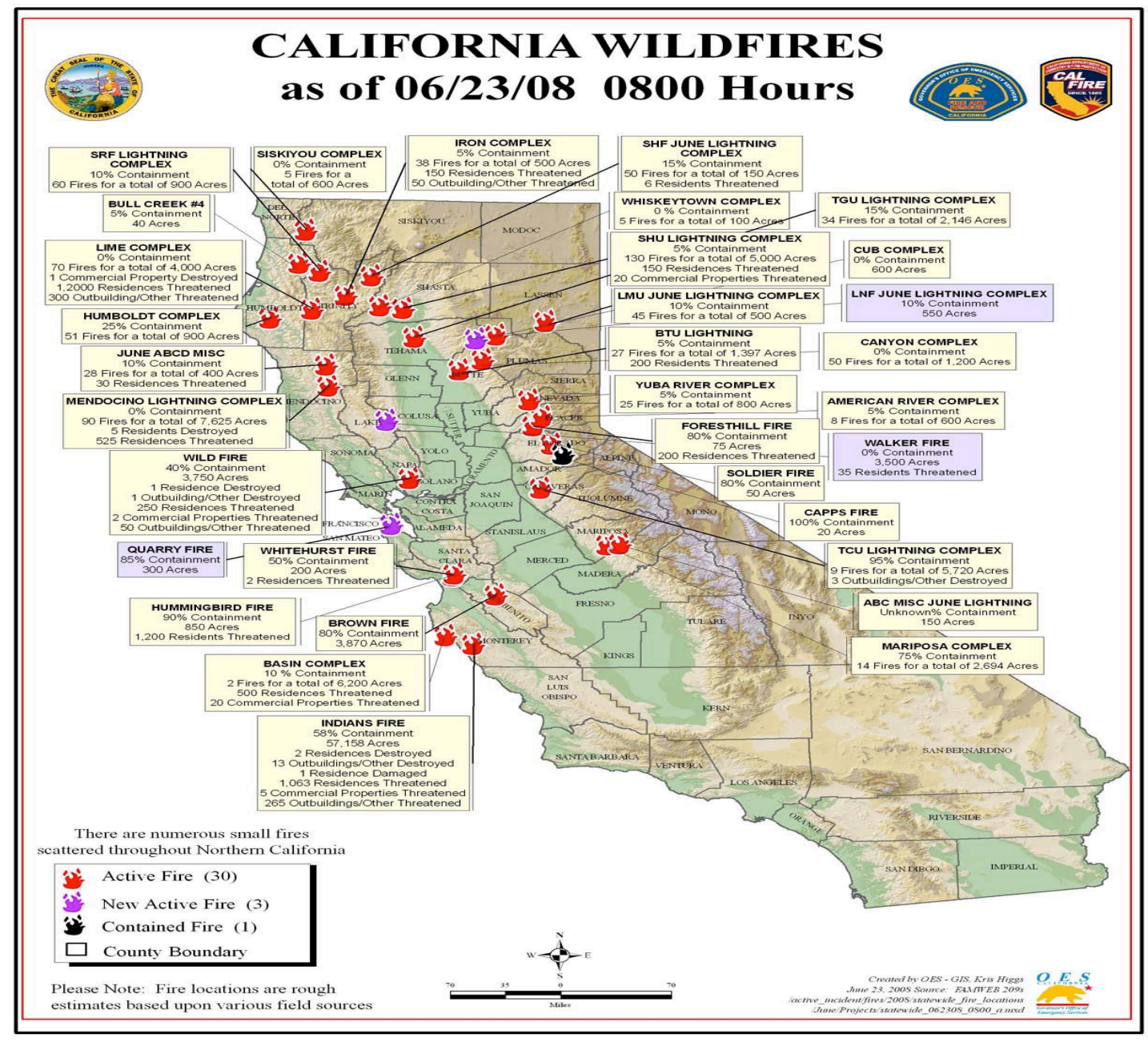

Fig. 1: Purple and red flame symbols indicate new and ongoing fires or complexes as of 0800 UTC on 23 June 2008 (Courtesy of the California Office of Emergency Services). [Available online at http://www.fire.ca.gov/about/downloads/Statewide_Fire_Maps/ StatewideFireMap_062308.pdf] 


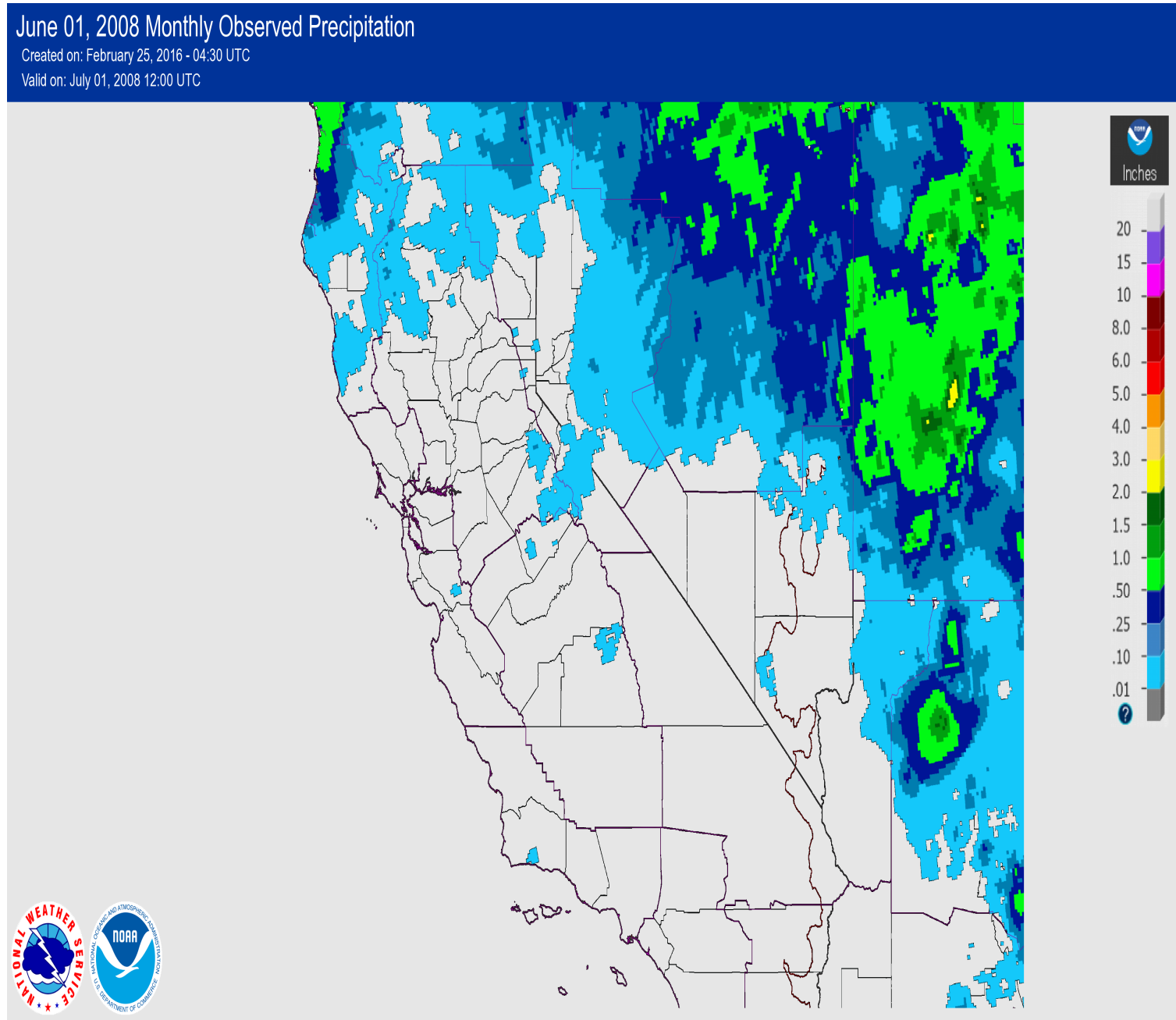

Fig. 2: Monthly observed precipitation (in) for June 2008. [Available at http://water.weather.gov/precip/] 


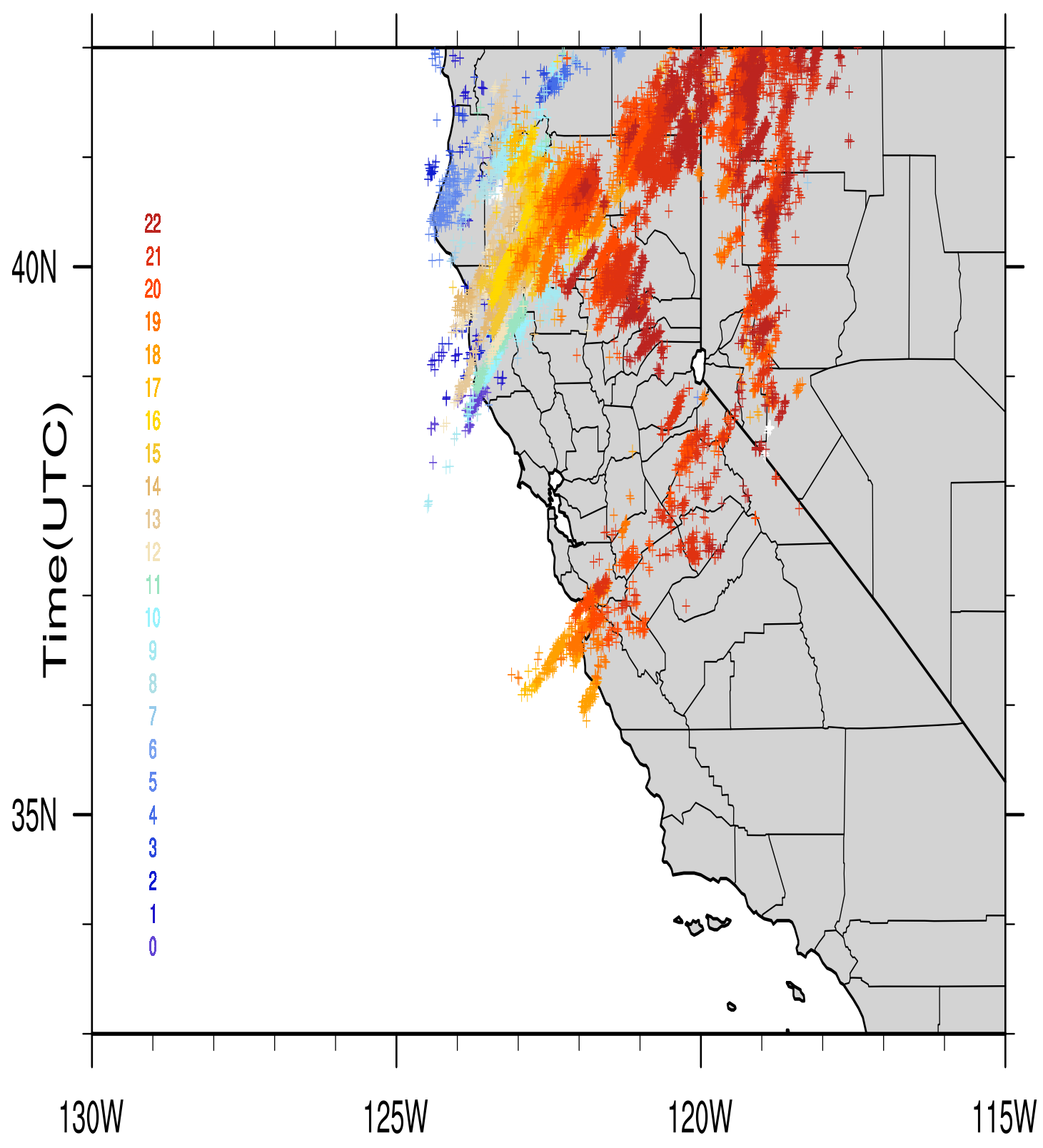

Fig. 3: This plot shows the location and timing of all lightning strikes on 21 June 2008. Storms came ashore on the northern coastal counties of California around and just after midnight local time (0700 UTC). Storms in the Monterey Bay region appeared around 11:00 am local time (1800 UTC) and continued onshore and inland into the afternoon. 


\section{Background}

Thunderstorms during the summer months in coastal California are rare and forecasting events such as the June 2008 dry lightning outbreak remains challenging, given the lack of available historical data. Dry lightning can easily ignite stressed vegetation and other fuels, and can produce gusty winds at the surface that result in fast-moving wildfires that threaten life and property. As global temperatures increase due to climate change, findings from Romps et al. (2014) suggest that lightning frequency will also increase by $7-17 \%$ per degree Celsius of warming across the contiguous United States. Additionally, Price (2009) postulates that lightning frequency is likely to increase even in regions that receive less precipitation in the decades to come. With enough lead time, fire-fighting authorities can position available assets and help mitigate the danger. Our research uses the June 2008 outbreak as a benchmark case study to offer a comprehensive investigation into the current understanding of dry lightning outbreaks in the western US, and provide an update on the performance of convection-resolving mesoscale models that may prove useful for forecasting such events.

Despite their rarity over coastal California (fewer than 5 days per year on average; Ahrens 2012), thunderstorms that do form along much of the west coast of the US often develop alongside conditions that are favorable for dry lightning. Rorig and Ferguson (1999) compared 30 years of sounding data in the northwest US with lightning and precipitation data to identify variables that can distinguish 
between wet and dry thunderstorms. Through statistical F-Test analysis, they determined that the $850 \mathrm{hPa}$ dewpoint depression $\left(\mathrm{T}_{850}-\mathrm{Td}_{850}\right)$ and the $850-$ $500 \mathrm{hPa}$ temperature difference $\left(T_{850}-\mathrm{T}_{500}\right)$ were the only two significant variables that could be used to discriminate between the two. The average 850 $\mathrm{hPa}$ dewpoint depression and $850-500 \mathrm{hPa}$ temperature difference were both found to be larger for dry storms $\left(13.2{ }^{\circ} \mathrm{C}\right.$ and $31.6{ }^{\circ} \mathrm{C}$ respectively) over Spokane, WA. Their method of discrimination was able to correctly classify 58$74 \%$ of storms at several stations across the northwest and of these storms, 70 $80 \%$ were found to be dry thunderstorms.

The findings from Rorig et al. (1999) would suggest that a dry layer underneath an elevated instability source is necessary to identify dry thunderstorms. Convection generated by elevated instability will likely have a cloud base and primary inflow well above the planetary boundary layer. If the dry layer underneath the elevated convection is deep enough, most of the precipitation that falls will evaporate before reaching the ground. Along the west coast, surface-based convection is often suppressed due to the stabilizing effects on the boundary layer by the cold Pacific waters. It is reasonable to assume that robust convection offshore from the west coast requires an elevated source of instability.

This logic has provided a foundation to build on for dry lightning forecasts. In a later study by Rorig et al. (2007), the established algorithm that compared the 850 dewpoint depression and 850-500 temperature difference was 
implemented in an operational setting and applied to numerical model forecasts in a case study of the northwest United States. Instead of interpolating data to a specific pressure level, data were pulled from specific terrain-following sigma levels that relax with height and correspond roughly with needed pressure levels over Spokane, WA. The sigma levels are used as the vertical coordinate in the fifth-generation Pennsylvania State University-National Center for Atmospheric Research Mesoscale Model (MM5) and allow the probability calculations to be performed for locations that may exist above the desired pressure levels. The algorithm assigns a probability for dry convection over each grid point. Rorig et al. (2007) found that $98 \%$ of all fires in the case study were collocated in regions that had a $75 \%$ probability or greater of being dry convection. The main drawback of their method is that it only distinguishes between dry and wet convection should it occur in a given location, but does not provide a probability of the convection itself occurring. The algorithm depicted a large area of $70-80 \%$ probability of dry convection, but only a few pixels contained fires, which resulted in a large false alarm ratio.

It is clear that several elements must superimpose to trigger dry lightning convection. Sufficient moisture and conditional instability must be present in conjunction with a lifting mechanism in the middle levels of the atmosphere for dry lightning formation. Wallman et al. (2010) developed a procedure to help forecast dry lightning outbreaks in an operational setting and used the June 2008 California outbreak as one of their case studies. This procedure includes a 250 
$\mathrm{hPa}$ wind analysis, tropopause pressure analysis, upper level lapse rate and High Level Total Totals index (HLTT) analysis, and analysis of equivalent potential temperature $\left(\theta_{\mathrm{e}}\right)$ above the planetary boundary layer. The $250 \mathrm{hPa}$ wind analysis tracks lift that may be attributed to transverse ageostrophic circulations connected with upper level jet streaks. Positive pressure advection at the tropopause has been connected with ascent upstream from the advection and can be used to more easily identify shortwave troughs (Hirschberg and Fritsch, 1991). Lapse rates evaluated from $500-300 \mathrm{hPa}$ greater than $7.5^{\circ} \mathrm{C} \mathrm{km}^{-1}$ are considered sufficiently unstable for elevated convection to occur. The HLTT index is an adjusted Total Totals index for elevated instability that combines 700 $\mathrm{hPa}$ and $500 \mathrm{hPa}$ temperatures and dew points to assess potential thunderstorm development. HLTT values greater than $25^{\circ} \mathrm{C}$ in the western states of the US indicate high probability of widespread thunderstorms. $\theta_{\mathrm{e}}$ analysis is used to locate low-level fronts, if they exist, and therefore convergence and is suggested by Moore et al. (1998) in forecasting elevated convection. Most Unstable Convective Available Potential Energy (MUCAPE) was discussed as a potential indicator of instability as it can identify layers of conditional instability in any of the lowest $300 \mathrm{hPa}$ of the atmosphere.

In the case of the June 2008 outbreak, the procedure developed by Wallman et al. (2010) gave mixed signals as to whether dry lightning was likely. In a Nevada outbreak that was examined, nearly all attributes of the procedure were skillful. The upper level lapse rates provided the most skill in both case 
studies compared with the other analyses in the procedure. It is suggested that their procedure may yield better results when used in conjunction with ensemble forecasting techniques.

Nauslar et al. (2013) suggested an additional approach to forecast dry lightning. Their method considers the upper level lapse rate analysis that was used by Wallman et al. (2010) as well as isentropic cross-sectional analysis. In regions where the upper level lapse rates exceed the $7.5^{\circ} \mathrm{C} \mathrm{km}^{-1}$ threshold, cross sections of $\theta_{\mathrm{e}}$ and water vapor mixing ratio can highlight areas of lower and mid-level instability and the existence of a dry layer beneath. This type of analysis combines the effects of several important factors into one analysis to assess the potential for dry lightning development. Nauslar et al. (2013) explain that jet streak divergence aloft can influence dry thunderstorm development even if it is not directly overhead, provided that other favorable conditions are also present.

Most of these indices connect elevated instability with convection potential, but do not necessarily address the microphysical properties associated with cloud electrification. There are many mechanisms that can transfer charge through particles within a cloud, but many of them do not occur on scales large enough to explain cloud electrification. Saunders (2008) provides an extensive summary of these mechanisms. The most likely mechanism responsible for charge separation in clouds is the non-inductive charging of ice particles that occurs when they rebound from collisions with riming graupel, possibly through 
the meltwater. Bruning et al. (2012) explain that the riming rate of graupel particles can affect their polarity as well as the polarity of smaller ice particles that they may collide with. A high-resolution cloud model would be necessary to further explore the microphysical properties of dry lightning and elevated convection.

\section{Experiment Design}

Forecasters rely heavily on numerical models for guidance in making their forecasts. It is generally good practice to consult multiple models and ensembles when available. In order to tease out the key features of the June 2008 event from an operational standpoint, the same practices are applied here. Analysis data (F0 hour) from the Global Forecast System (GFS) and the North American Mesoscale Forecast System (NAM) models were used to track this storm system as it evolved. Then, forecast data from GFS and NAM were used as initial boundary conditions to run a mesoscale model in order to capture convective scale elements of this outbreak, and determine viability of current lightning forecasting methods. This data was made publicly available by and collected from the NOAA National Operational Model Archive and Distribution System (available at http://nomads.ncdc.noaa.gov/).

First, analysis data from the GFS model was selected to determine evolution characteristics of this storm as it approached the US west coast. The $0.5^{\circ} \times 0.5^{\circ}$ global grid provides access to a larger domain of atmospheric 
conditions as well as a longer ingest period for data assimilation before GFS is initialized. We investigated model analysis data in 12-hour intervals preceding the time of convective initiation near Monterey Bay (21 June 2008 at 1800 UTC) to track the overall evolution of the storm and identify missing elements from the forecast discussions. The analysis times selected are listed in Table 1 as well as their relation to the time of the outbreak. All data visualization and analysis was performed with the Integrated Data Viewer (IDV version 5.1) software from UCAR/Unidata as well as the NCAR Command Language (NCL Version 6.2.2).

Table 1: GFS Analysis data in relation to 21 June 2008 at 1800 UTC

\begin{tabular}{|c|c|}
\hline Analysis Time & Relation to Outbreak \\
\hline 20 June $2008-0600$ UTC & $\mathrm{T}-36 \mathrm{hrs}$ \\
\hline 20 June $2008-1800$ UTC & $\mathrm{T}-24 \mathrm{hrs}$ \\
\hline 21 June $2008-0600$ UTC & $\mathrm{T}-12 \mathrm{hrs}$ \\
\hline 21 June $2008-1800$ UTC & $\mathrm{T}=0$ \\
\hline 22 June $2008-0600$ UTC & $\mathrm{T}+12 \mathrm{hrs}$ \\
\hline
\end{tabular}

Next, the Weather Research and Forecasting mesoscale model with Advanced Research WRF core (WRF-ARW Ver. 3.5.1) was used to resolve and forecast the finer, convective scale elements of the simulated storm system as it approached the California coastline. The WRF configurations used by the Monterey NWS office (http://www.wrh.noaa.gov/mtr/mtrwrfdoc.pdf) were used for these simulations. Lateral boundary conditions were supplied from either GFS or NAM forecasts at 3-hour intervals. We selected five forecast cycles leading up to 
the outbreak to create operational hindcasts. Table 2 contains information about WRF-GFS simulation times and Table 3 outlines simulation times for WRF-NAM runs.

Table 2: WRF-GFS members and relation to 21 June 2008 at 1800 UTC

\begin{tabular}{|l|l|l|}
\hline $\begin{array}{l}\text { WRF-GFS } \\
\text { Simulation }\end{array}$ & Forecast Cycle & $\begin{array}{l}\text { Time Difference from } \\
\text { Outbreak }\end{array}$ \\
\hline G1 & 19 June 2008 - 1200 UTC & $-54 \mathrm{hrs}$ \\
\hline G2 & 20 June 2008 - 0000 UTC & $-42 \mathrm{hrs}$ \\
\hline G3 & 20 June 2008 - 1200 UTC & $-30 \mathrm{hrs}$ \\
\hline G4 & 21 June 2008 - 0000 UTC & $-18 \mathrm{hrs}$ \\
\hline G5 & 21 June 2008 - 1200 UTC & $-6 \mathrm{hrs}$ \\
\hline
\end{tabular}

Table 3: WRF-NAM members and relation to 21 June 2008 at 1800 UTC

\begin{tabular}{|l|l|l|}
\hline $\begin{array}{l}\text { WRF-NAM } \\
\text { Simulation }\end{array}$ & Forecast Cycle & $\begin{array}{l}\text { Time Difference from } \\
\text { Outbreak }\end{array}$ \\
\hline N1 & 19 June 2008 - 1200 UTC & $-54 \mathrm{hrs}$ \\
\hline $\mathrm{N} 2$ & 20 June 2008 - 0000 UTC & $-42 \mathrm{hrs}$ \\
\hline $\mathrm{N} 3$ & 20 June 2008 - 1200 UTC & $-30 \mathrm{hrs}$ \\
\hline $\mathrm{N} 4$ & 21 June 2008 - 0000 UTC & $-18 \mathrm{hrs}$ \\
\hline $\mathrm{N} 5$ & 21 June 2008 - 1200 UTC & $-6 \mathrm{hrs}$ \\
\hline
\end{tabular}

Essentially, we generated an ensemble of 5 simulations with GFS input, and 5 with NAM input started at 12-hour intervals. Together, these produce 10 forecasts at the time lightning was detected off the Monterey coastline (approximately 1800 UTC on 21 June 2008). A horizontal grid resolution ( $\Delta x$ and $\Delta y$ ) of $2 \mathrm{~km}$ was used to allow explicit simulation of convection and eliminate the need to run a convective parameterization scheme within the model. According to Baxter (2011), convective schemes present difficulties in simulating the effects 
of the diurnal cycle and it is suggested that the diurnal cycle plays in important role in elevated convection, at least in the central US. Schwartz et al. (2008) explain that $2 \mathrm{~km}$ grid resolutions only provide slight improvements to model simulated precipitation for larger convective complexes during the first 12 hours of simulation time compared with $4 \mathrm{~km}$ resolution. We decided to use a $2 \mathrm{~km}$ grid resolution due to the smaller-scale, isolated nature of convection in the Monterey Bay region. We used 45 vertical levels and designated $50 \mathrm{hPa}$ as the highest pressure level in WRF. The time step $(\Delta t)$ for the simulations was $10 \mathrm{sec}$ with a data-sampling (history) interval of 15 minutes. The WRF Single-Moment 6-class microphysics scheme (WSM6; Hong and Lim 2006) was selected for its capability to handle hail and graupel ice species, as the current body of literature suggests this is crucial to forecasting lightning.

Spatial distributions of simulated radar composite reflectivity (mdBZ) in conjunction with column maximum cloud fraction were used to identify stronger convective cells in the domain. Composite reflectivity is a more meaningful measure here as it identifies the maximum intensity of reflectivity from hydrometeors with a diameter of roughly $1-10 \mathrm{~mm}$ throughout a given grid column. By comparing these two parameters with observed lightning strikes, we can examine how each simulation performed. WRF hindcasts that showed convection in the vicinity of Monterey Bay were inspected thoroughly in comparison with other hindcasts. In addition to instability and moisture 
parameters, we tracked model graupel behavior to determine if WRF can forecast lightning.

McCaul et al. (2009) devised a lightning threat detection method that only requires ice specie mixing ratios (mainly graupel) and vertical wind speeds to compute. It is currently incorporated as an experimental analysis product of the High Resolution Rapid Refresh (HRRR) model. The group's analysis technique consists of a blend of two proxies. One assesses the magnitude of the lightning threat based on the graupel flux through the $-15^{\circ} \mathrm{C}$ isotherm and is weighted heavily (95\%). The other assesses the spatial distribution of the lightning threat as the sum of the vertically integrated ice, snow, and graupel species, and is weighted at $5 \%$. Only the graupel flux portion of the blended threat is used in our study as it has the greatest contribution to the overall threat magnitude. McCaul et al. (2009) explain that the vertical ice integration is more useful in cases with complex, mature convection and large anvils, as is typical in the Central Plains.

\section{Synoptic Overview}

First, we will examine the evolution of mid-level conditions. The geopotential heights at $500 \mathrm{hPa}$ are shown in Figure 4, and indicate a long wave trough over the Gulf of Alaska with an embedded short wave propagating toward the Pacific Northwest. The tilt of the short wave trough progresses from positively tilted at 36 hours prior, to neutral tilt at 24 hours prior, and acquires a negative tilt at 12 hours prior. The trough axis extends to northern California at zero hour and 
has lifted over Washington by 12 hours after the event with a new short wave trough forming over the northern Pacific Ocean. There are ridges over southern California and also north of Hawaii over the central Pacific Ocean at 36 hours prior. The ridges become less pronounced by the time of the lightning event and 12 hours after. There are vorticity maxima associated with the parent trough as well as the short wave as it traverses the Pacific. By 12 hours after the event, a new vorticity maximum is collocated with the digging short wave over the northern Pacific Ocean.

The $500 \mathrm{hPa}$ temperature advection evolution can be inferred from Figure 5. Strong warm air advection is noted east of the trough as it approaches the California coast at 24 and 12 hours prior. This would promote height falls below and aid in lift that could support convection. Cold air advection in the entire eastern Pacific region is relatively weak.

The conditions at $700 \mathrm{hPa}$ (Figure 6) are analogous to upper level conditions. Vorticity maxima associated with the broad trough are located over the Gulf of Alaska with an embedded short wave cutting eastward across the Pacific Ocean. A second short wave trough begins to form near the Aleutian Islands at 12 hours prior. The ridge centers are collocated with the upper level ridges at 36 hours prior and decrease in amplitude by the event time. The main deviation from upper level conditions is a weak inverted trough and associated local vorticity maximum located at roughly $24^{\circ} \mathrm{N}, 133^{\circ} \mathrm{W}$. Cold air advection at $700 \mathrm{hPa}$ (Figure 7) is noted just to the west of the trough axis and encourages 
divergence near the surface at 36,24 , and 12 hours prior. Weak warm air advection at this level is noted off the coast of Oregon and Washington.

Closer to the surface at $925 \mathrm{hPa}$, the short wave trough is more dominant than other features. Figure 8 shows a vorticity maximum coincident with a circulation center slightly east of the upper level short wave trough at 36 hours prior. At 24 and 12 hours prior, vorticity is transferred from the short wave trough as it weakens, first to the parent trough, and then to a newly developing trough to the west at the event time and 12 hours after. Meanwhile, a ridge expands across the Pacific Ocean from just north of Hawaii to the California coastline by 12 hours after the event. In Figure 9, cold air advection is marked on the west side of the circulation center offshore from the California/Oregon border at 24 and 12 hours prior. 

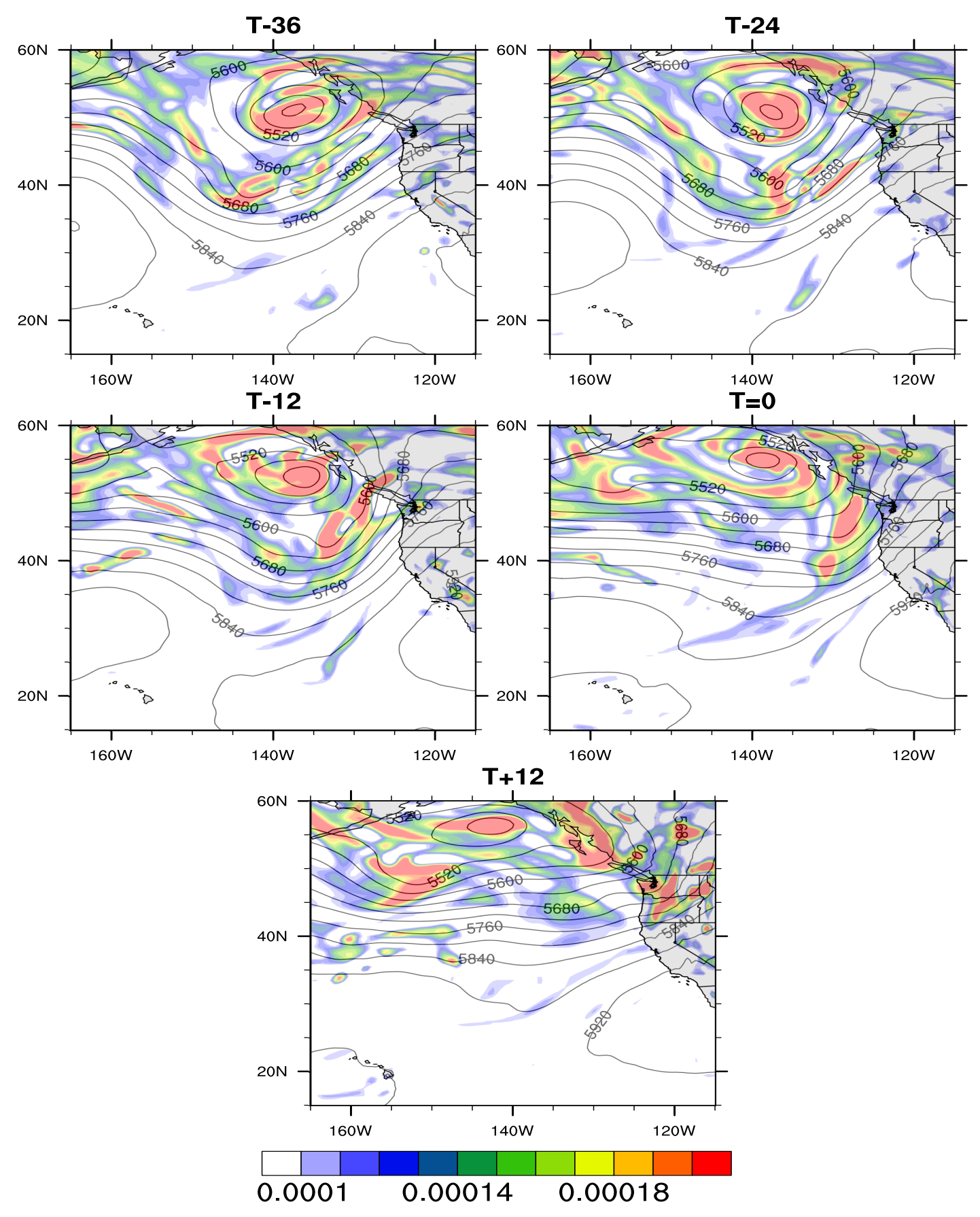

Fig. 4: Evolution of the $500 \mathrm{hPa}$ geopotential heights (contours, GPM) and absolute vorticity (filled, $\mathrm{s}^{-1}$ ) from GFS analysis data (0-hour forecast). Here, $T=0$ is representative of the convection outbreak in the Monterey Bay, 1800 UTC on 21 June 2008. 

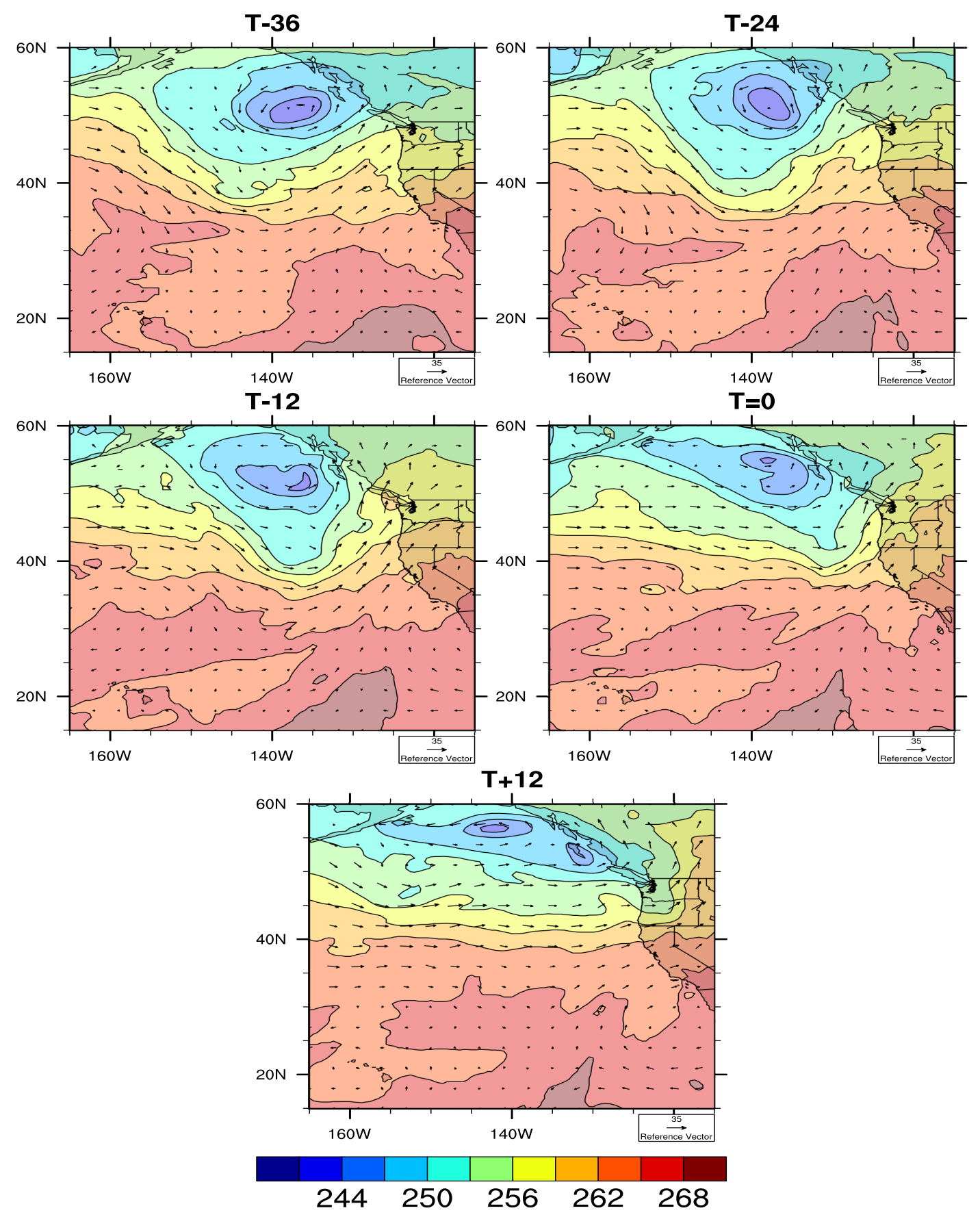

Fig. 5: Evolution of the $500 \mathrm{hPa}$ temperature (filled, $\mathrm{K}$ ) and winds (vectors) from GFS analysis data ( 0 -hour forecast). Here, $T=0$ is representative of the convection outbreak in the Monterey Bay, 1800 UTC on 21 June 2008. 


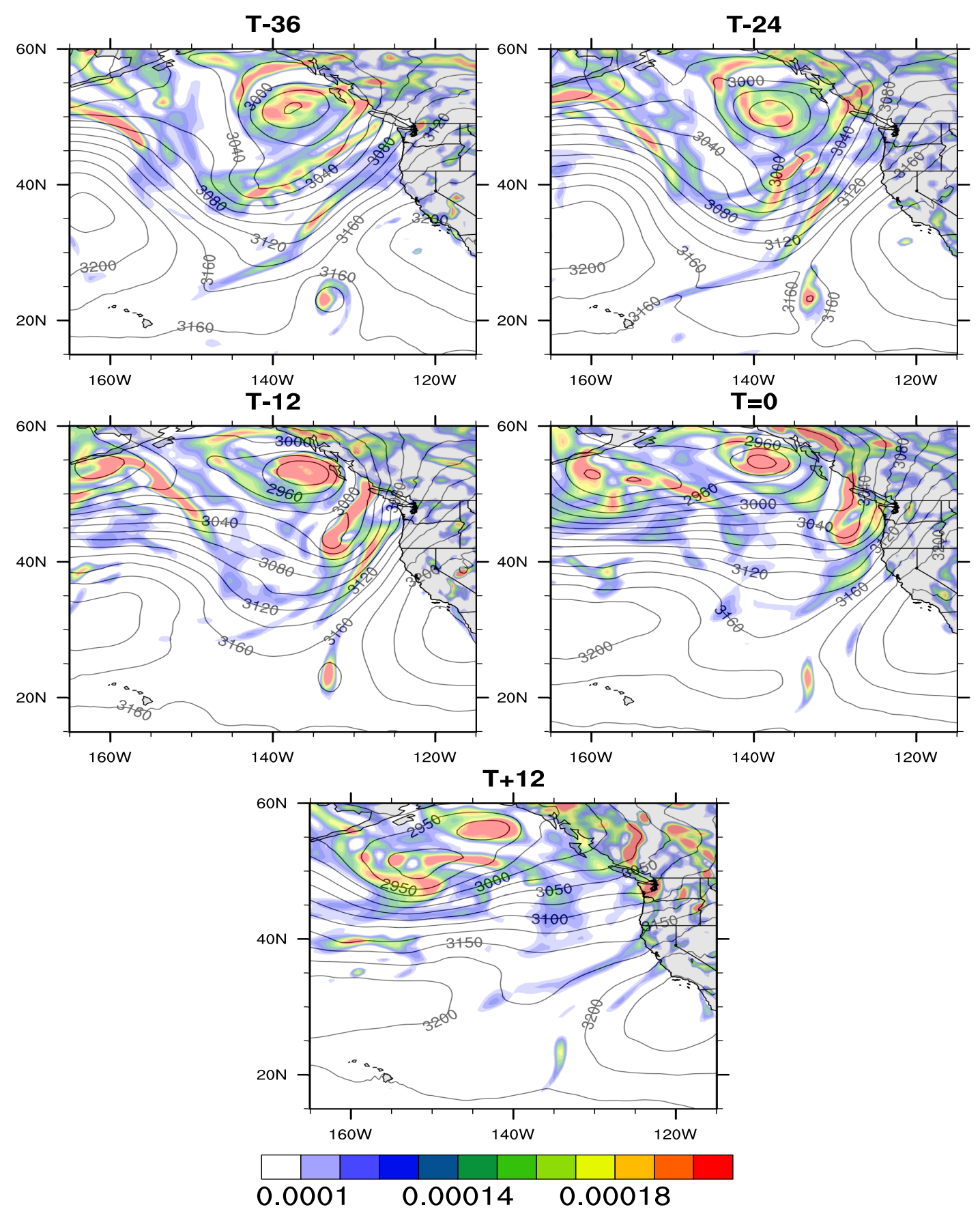

Fig. 6: Evolution of the $700 \mathrm{hPa}$ geopotential heights (contours, GPM) and absolute vorticity (filled, $\mathbf{s}^{-1}$ ) from GFS analysis data $(0$-hour forecast). Here, $T=0$ is representative of the convection outbreak in the Monterey Bay, 1800 UTC on 21 June 2008. 

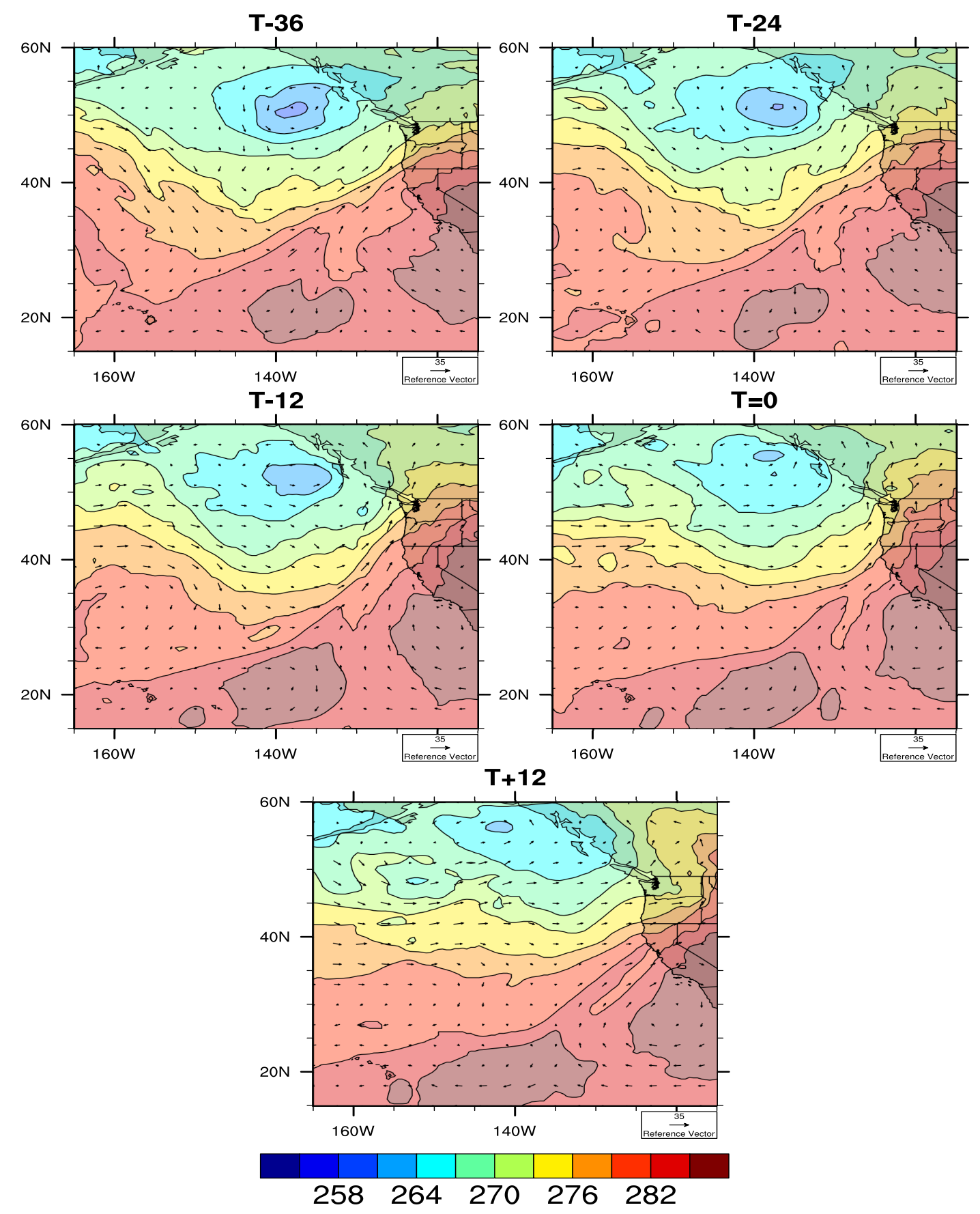

Fig. 7: Evolution of the $700 \mathrm{hPa}$ temperature (filled, $\mathrm{K}$ ) and winds (vectors) from GFS analysis data ( 0 -hour forecast). Here, $T=0$ is representative of the convection outbreak in the Monterey Bay, 1800 UTC on 21 June 2008. 


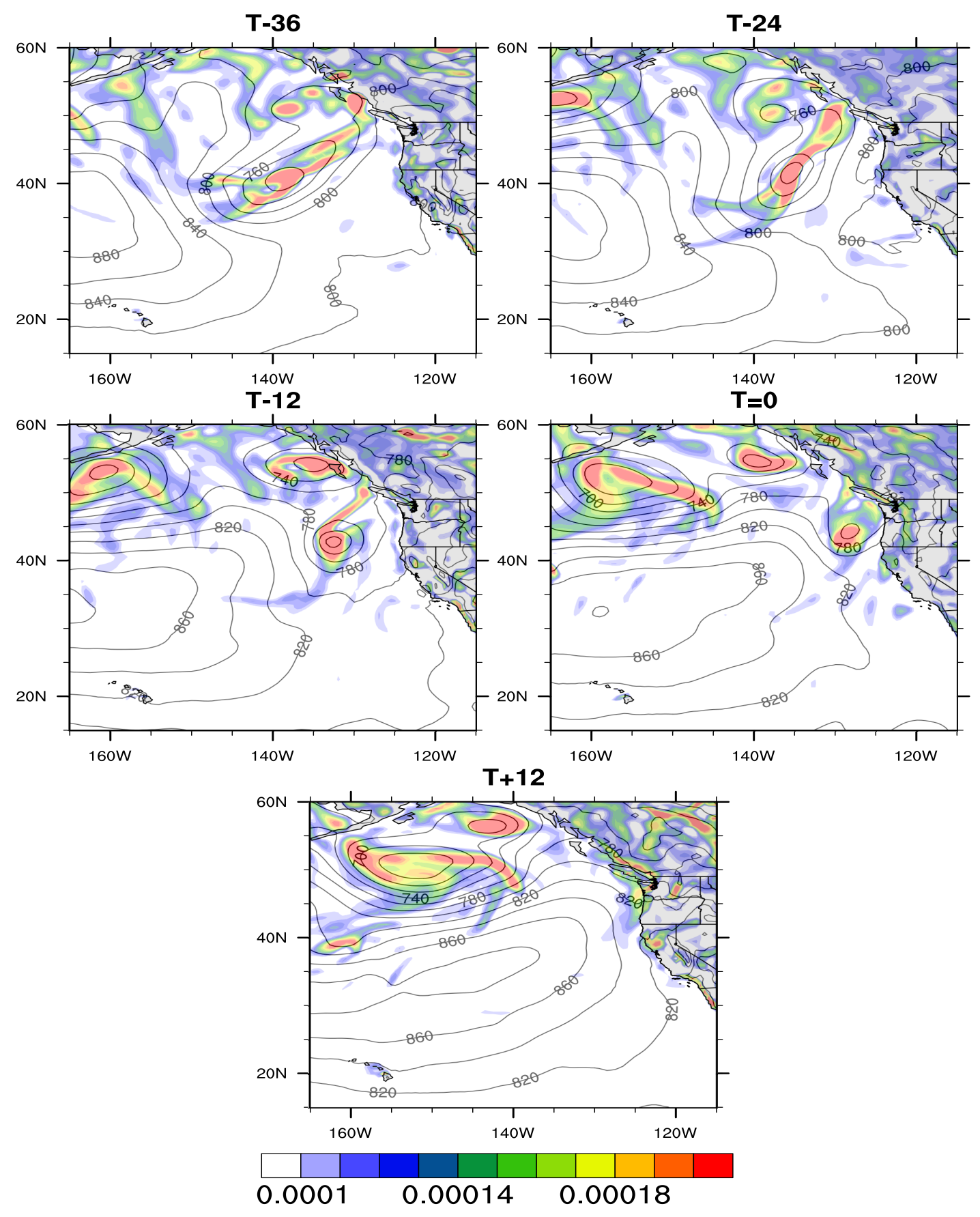

Fig. 8: Evolution of the $925 \mathrm{hPa}$ geopotential heights (contours, GPM) and absolute vorticity (filled, $\mathbf{s}^{-1}$ ) from GFS analysis data $(0$-hour forecast). Here, $T=0$ is representative of the convection outbreak in the Monterey Bay, 1800 UTC on 21 June 2008. 
T-36

T-24
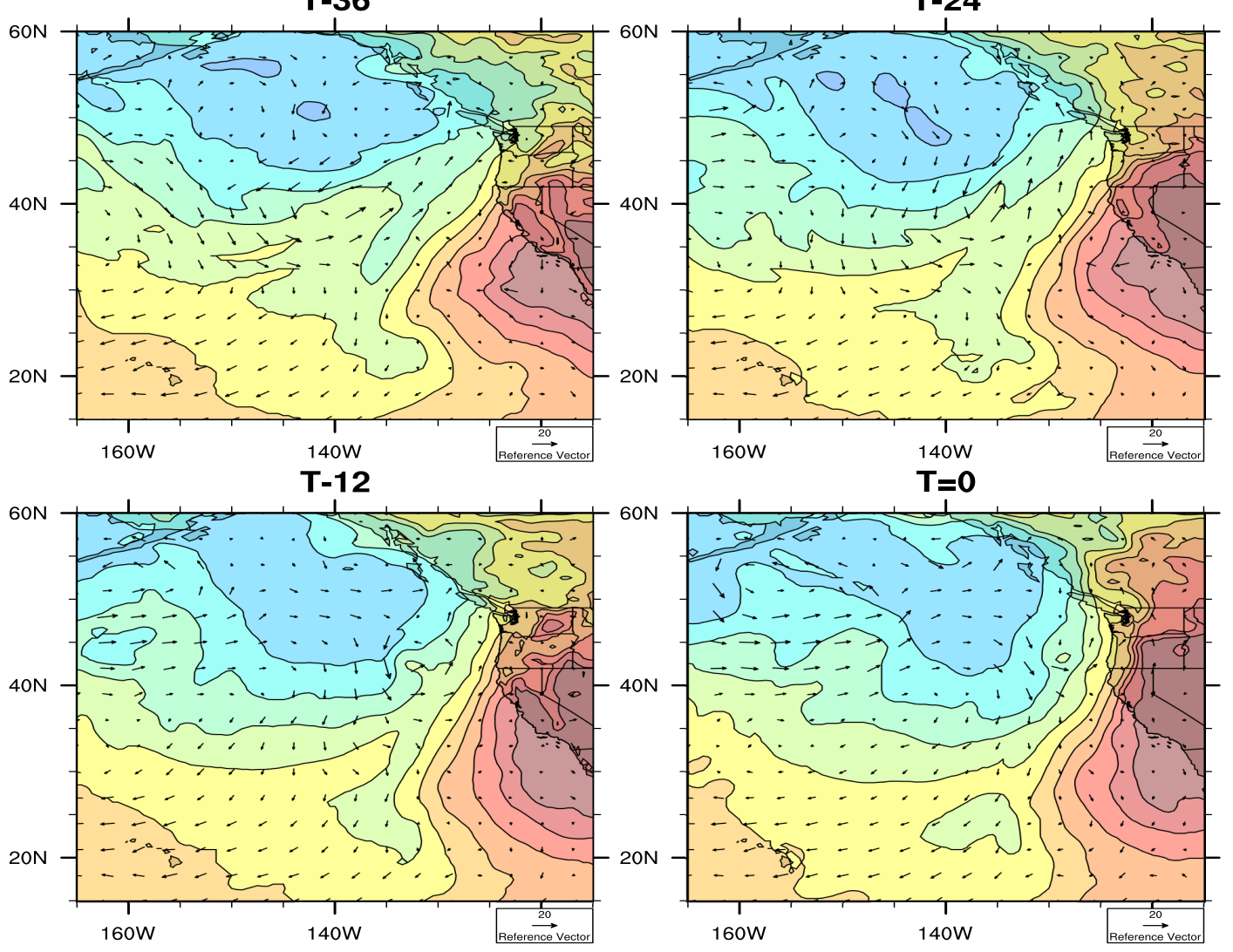

$T+12$

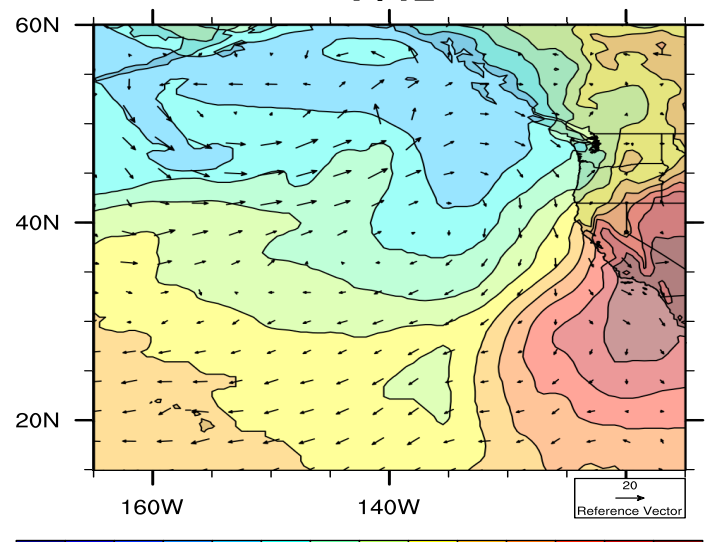

266272278284290296302

Fig. 9: Evolution of the $925 \mathrm{hPa}$ temperature (filled, $\mathrm{K}$ ) and winds (vectors) from GFS analysis data ( 0 -hour forecast). Here, $T=0$ is representative of the convection outbreak in the Monterey Bay, 1800 UTC on 21 June 2008. 
Upper level fronts or tropopause folds can be used to identify regions where forcing promotes lift in the mid to lower atmosphere. The 1.5 or 2.0 potential vorticity unit (PVU) pressure can be used to determine the height of the dynamic tropopause. Figure 10 shows the pressures on the 2 PVU surface, and thus indicates the height of the tropopause in the GFS model. Four features are evident: first is a pressure maximum of $450 \mathrm{hPa}$ over the Gulf of Alaska and across western Canada associated with the parent long wave trough. This indicates that the tropopause is lowered, as is typical (Lackmann 2011). The approaching short wave is visible as an extension of $300 \mathrm{hPa}$ tropopause pressure that encircles the parent trough. The second feature is a tropopause pressure minimum of less than $100 \mathrm{hPa}$ to the southwest of the Baja Peninsula (shown in purple). The third feature is a broad pressure minimum less than 140 hPa south of the Aleutian Islands that follows the short wave trough eastward, across the Pacific. The last feature is the interface region between the Baja minimum and the high values over the Gulf of Alaska. This interface is clearly defined on June $19^{\text {th }}$ at 0000 UTC and extends from central California to due east of Hawaii. Along this interface, numerous tropopause ripples and undulations with pressure differences of over $100 \mathrm{hPa}$ are advected over central California. One such feature is shown clearly in Figure 11 between 0600 UTC and 1200 UTC on 21 June 2008. This was just before convection initiated over the Monterey Bay. 


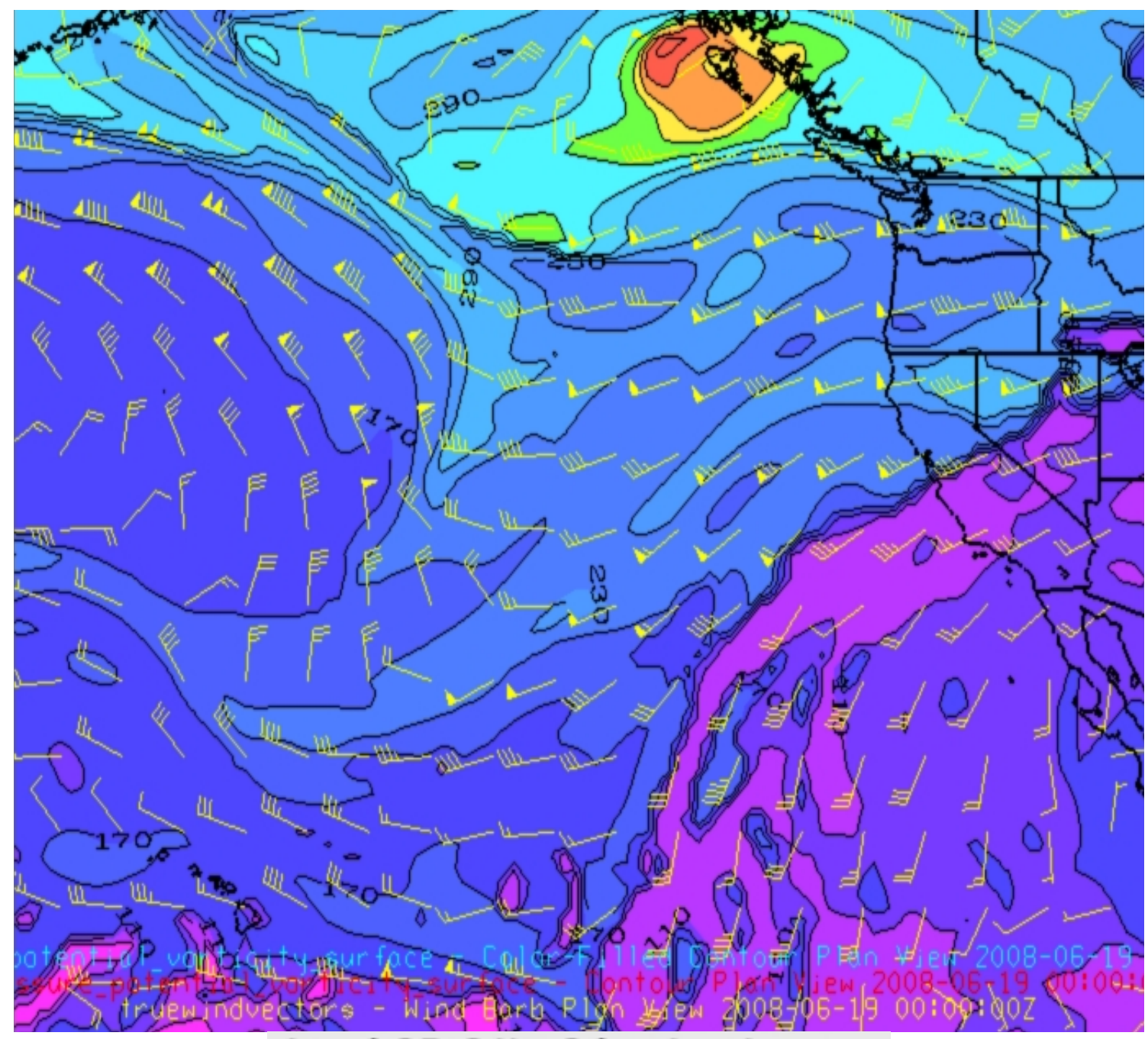

Level: $2 \mathrm{E}-6 \mathrm{~K} \mathrm{~m} 2 \mathrm{~kg}-1 \mathrm{~s}-1$

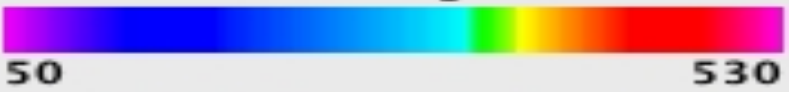

Fig. 10: 2 PVU pressure (hPa) with wind barbs at the $2 \mathrm{PVU}$ level from GFS analysis data (0-hour forecast) valid 19 June 2008 at $0000 Z$. 


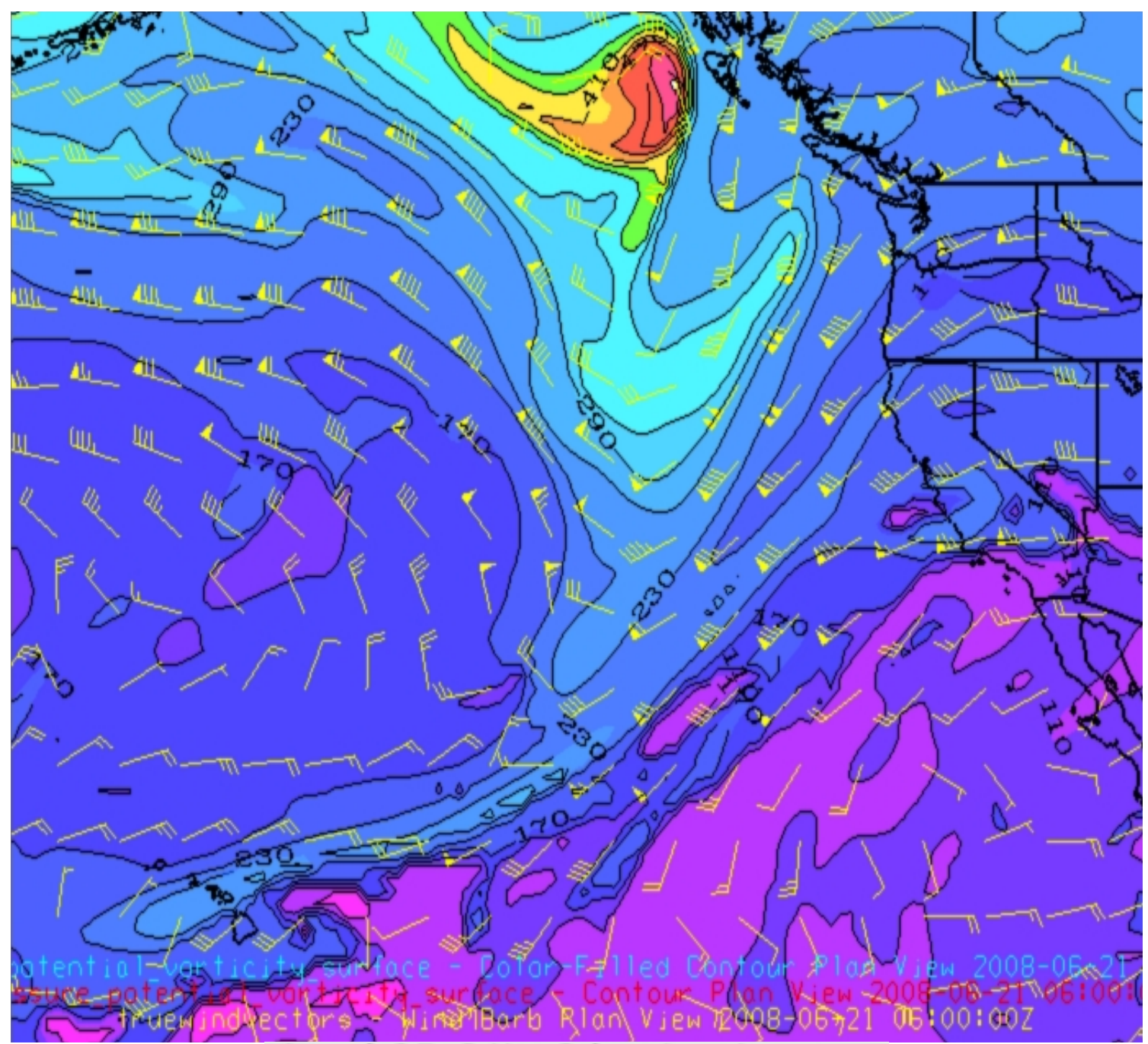

Level: $2 \mathrm{E}-6 \mathrm{~K} \mathrm{~m} 2 \mathrm{~kg}-1 \mathrm{~s}-1$

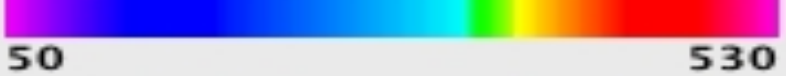

Fig. 11: 2 PVU pressure (hPa) with wind barbs at the 2 PVU level from GFS analysis data (0-hour forecast) valid 21 June at $0600 Z$. 
We employ the Q-vector form of the quasi-geostrophic omega equation to diagnose forcing for vertical motions throughout the domain by calculating the Qvector divergence (Lackmann 2011). Positive (negative) divergence indicates forcing for descent (ascent). Figure 12 shows the evolution of the Q-vector divergence at $700 \mathrm{hPa}$. The primary forcing for vertical motions are associated with the approaching short wave trough off the California coastline and the developing short wave near the Aleutian Islands. Here, red colors indicate forcing for descent and blue colors indicate forcing for ascent. In general, the forcing for upward and downward vertical motions appear together in couplets. Another region of vertical motion forcing is associated with a closed circulation and local vorticity maximum that was identified in the middle atmosphere $(700 \mathrm{hPa})$ at $24^{\circ} \mathrm{N}, 133^{\circ} \mathrm{W}$. This cyclone is visible at $850 \mathrm{hPa}$, but not below in the boundary layer. We will continue to investigate this eddy as a possible mechanism for injecting moisture aloft.

Streamline winds at $700 \mathrm{hPa}$ (Figure 13) indicate further that an eddy is present at $24^{\circ} \mathrm{N}, 133^{\circ} \mathrm{W} 36$ hours prior. This cyclonic eddy impedes typical easterly flow around the tropics, and helps to incorporate monsoonal moisture in the flow directed at California. The GFS model does not explicitly output moisture transport, but water vapor mixing ratio can be derived given temperature, relative humidity, and pressure. The cross-section in Figure 14 includes both the eddy and flow offshore, and demonstrates its enhancing effect on middle level water vapor. We see that four days prior to the event, most moisture in this region was 
confined below $1.5 \mathrm{~km}$ in the boundary layer. By three days prior, we see a lofted moist layer between 2-4 $\mathrm{km}$ with mixing ratios approaching $7 \mathrm{~g} \mathrm{~kg}^{-1}$ with a drier layer appearing between 1-2 km. At two days prior, the elevated moist layer approaches the Monterey Bay. By 24 hours prior, the moist layer begins to mix down toward the surface over the Monterey Bay and is still present at the time of the outbreak.

Evaluation of upper air jet streaks reveals additional evidence that favors convective activity farther to the south. In Figure 15, we tracked the evolution of wind speeds at the $250 \mathrm{hPa}$ level. At the time of the event, the jet core has a strong meridional (north-south) component and is situated just off the west coast. It should be noted that the Monterey Bay region is located within the right rear region of the jet at this time. The right rear jet region is associated with upward vertical motions in the lower atmosphere due to the ageostrophic circulations involved with jet dynamics. 
T-36
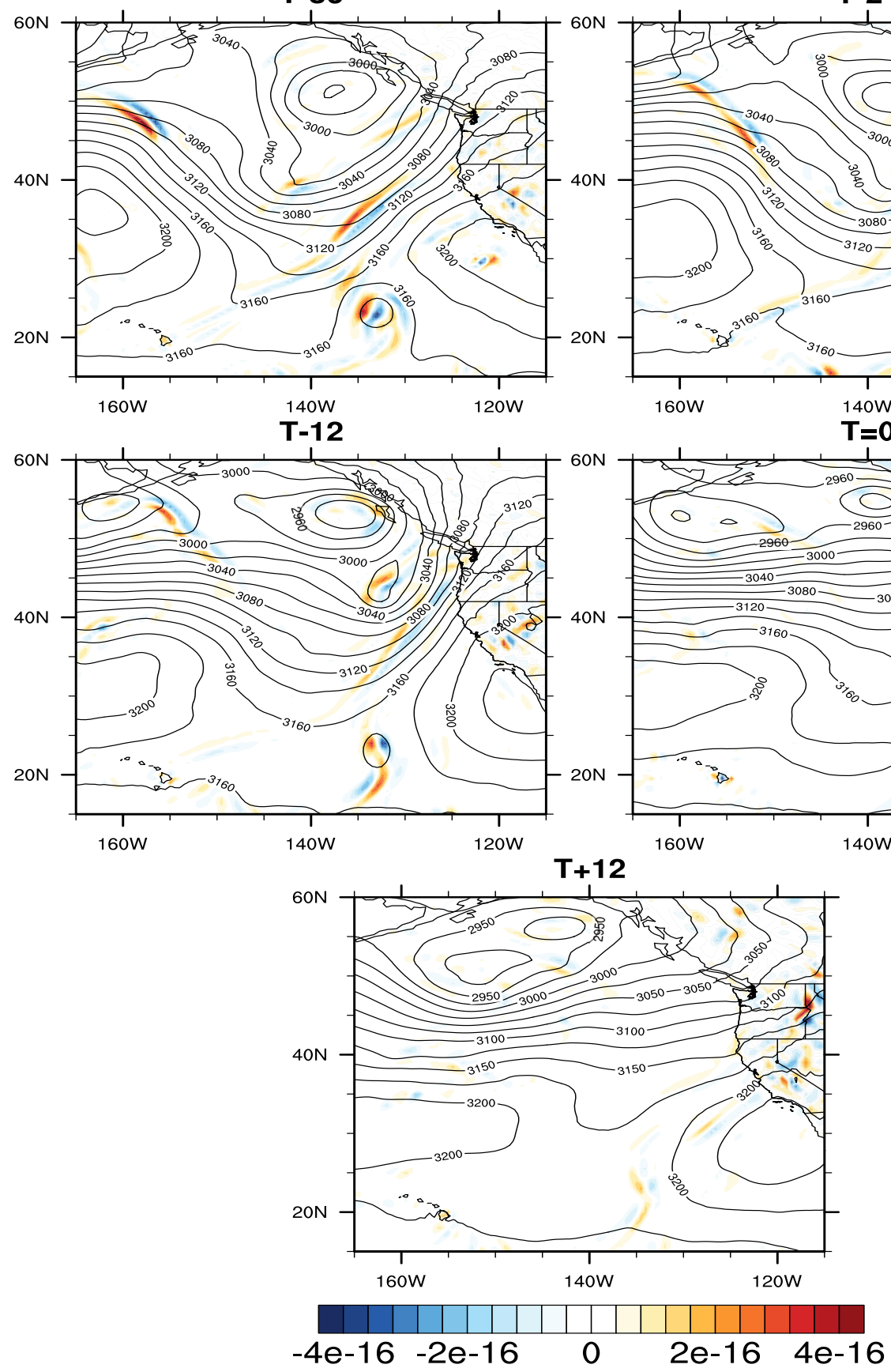

T-24
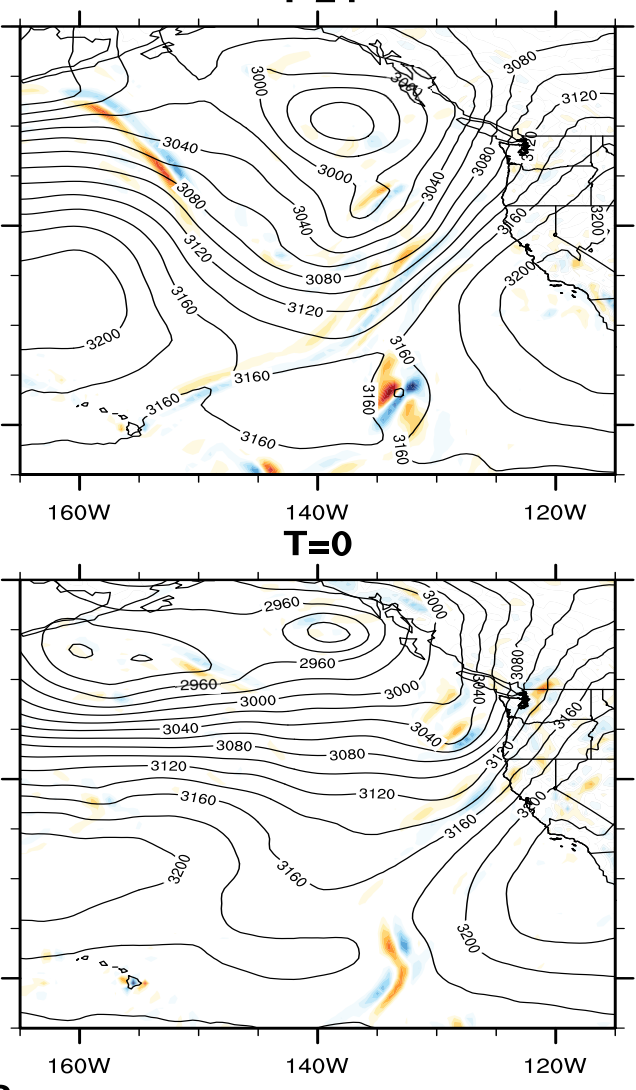

$$
\text { - }
$$




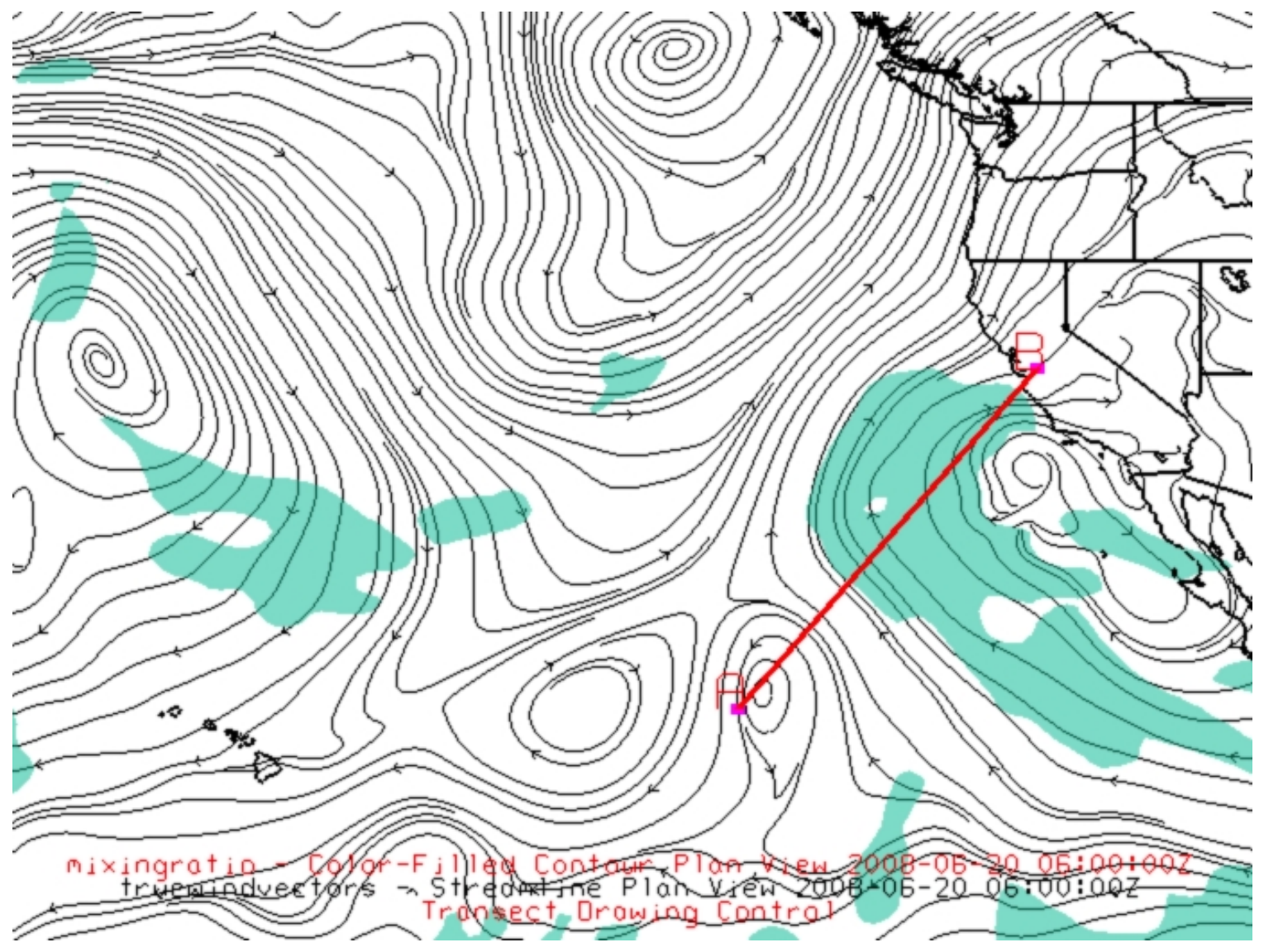

Fig. 13: Wind streamlines at $700 \mathrm{hPa}$ from GFS analysis data (0-hour forecast) for 20 June 2008 at $0600 Z$. Red line indicates transect line for Figure 14. Green shading indicates water vapor mixing ratios greater than $5 \mathrm{~g} \mathrm{~kg}^{-1}$ at $650 \mathrm{hPa}$. 
a)

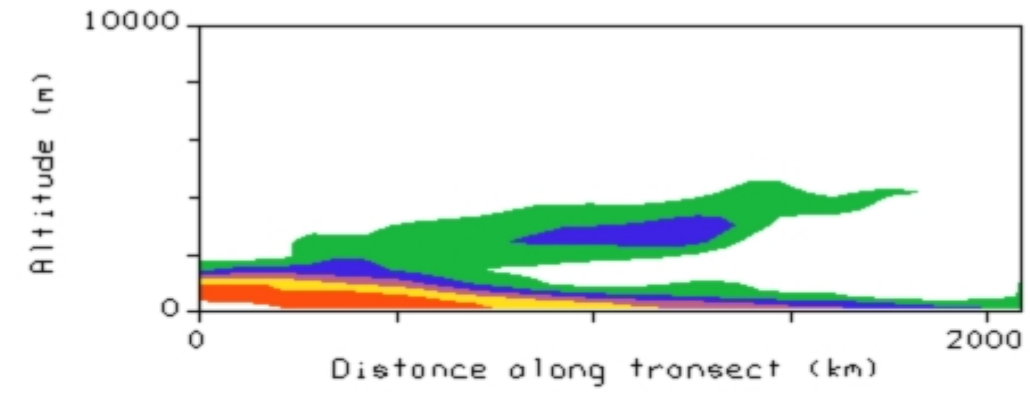

b)

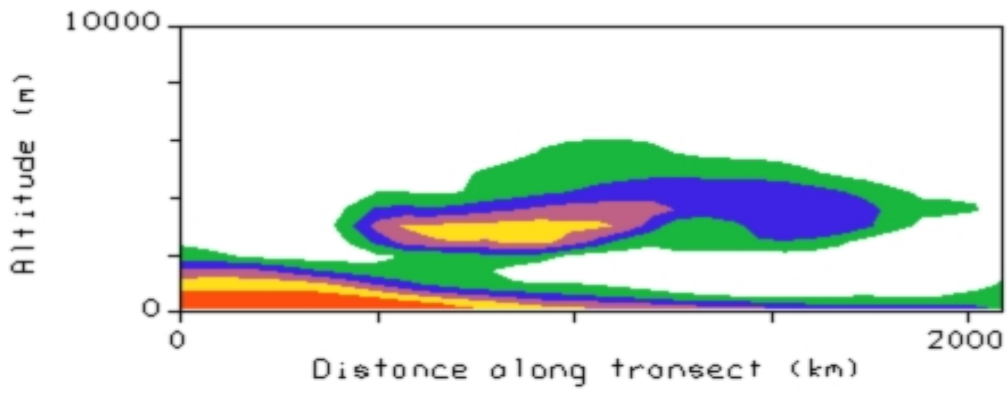

c)

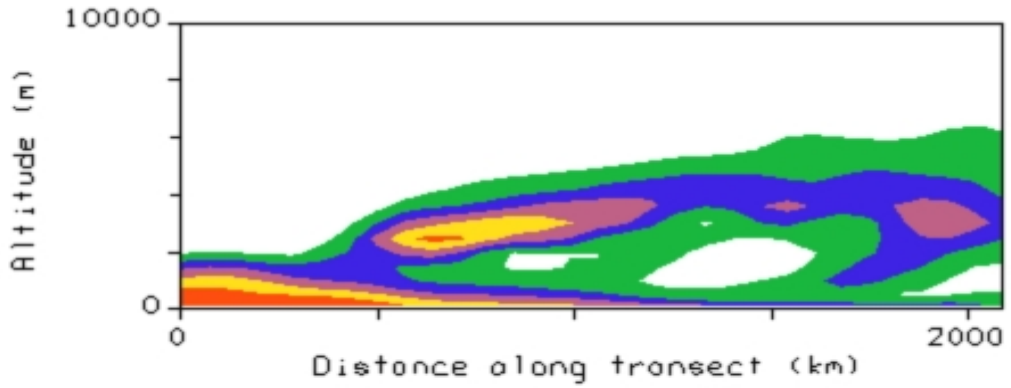

d)

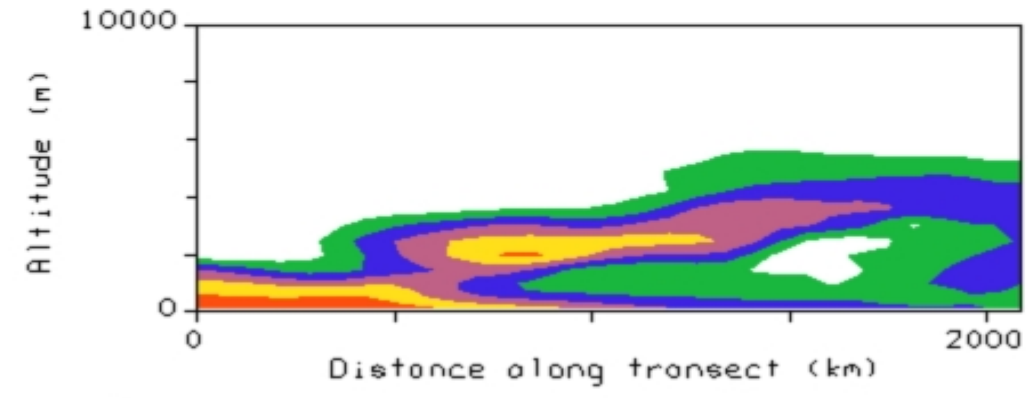

2

8

10

Fig. 14: Vertical cross-section of water vapor mixing ratio $\left(\mathrm{g} \mathrm{kg}^{-1}\right)$ from GFS analysis data (0-hour forecast) valid at 1200 UTC on a) 18 June 2008, b) 19 June 2008, c) 20 June 2008, and d) 21 June 2008 along transect from Figure 13. 

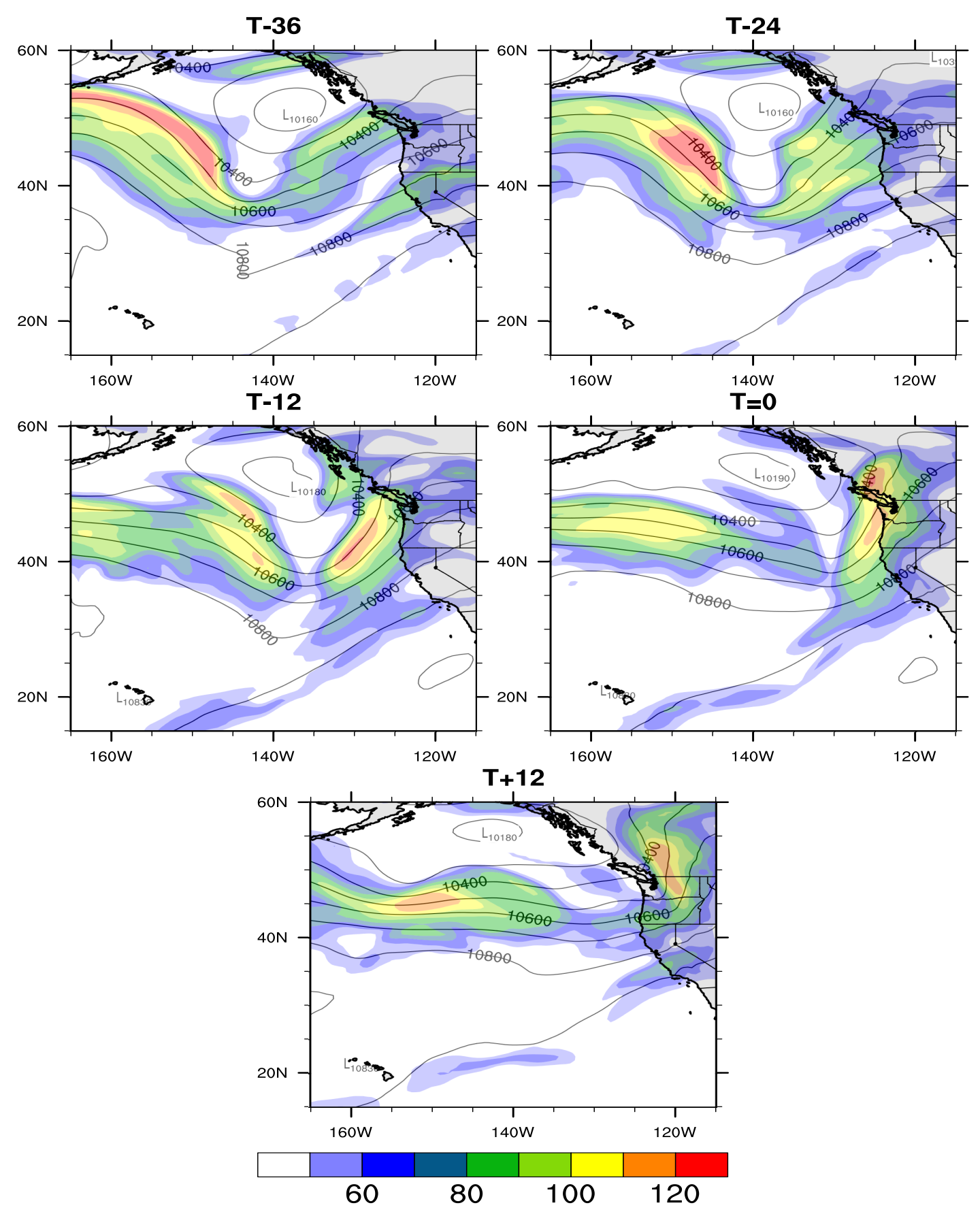

Fig. 15: Evolution of geopotential height (contour, GPM) and wind speed (fill, $\mathrm{mph}$ ) at the $250 \mathrm{hPa}$ level from GFS analysis data (0-hour forecast) with $\mathrm{T}=0$ set to 21 June 2008 at 1800 UTC. 


\section{WRF Simulations}

Having established how the storm evolved on the synoptic scale, we now ask: could/should a model such as WRF have been able to predict a dry lightning outbreak? This is the main goal of our study.

\section{a. Model Convection Verification}

Using either the GFS or NAM analyses to initialize WRF, we examine the evolution of convective-scale storm organization from WRF simulations. Simulated radar composite reflectivity (mdBZ) and column maximum cloud fraction were compared with lightning strike observations to examine model results and identify convection.

Here we will assume column maximum cloud fraction $>0.8$ is an analog to nadir visible satellite imagery to identify where convection was present in the simulations. Cloud fraction in WRF is calculated using the equation presented by Xu and Randall (1996) at every vertical level in the domain. It has important implications in the model's radiation budget and microphysics schemes. Figure 16 and later figures will show forecast results at 1900 UTC from our simulations start at the times given in Tables 2 and 3 . In Figure 16 high cloud fraction is noted just off the northwest coast of California associated with the approaching front in all WRF-GFS hindcasts. In hindcasts G3-G5, a secondary cloud train is discernible roughly $100 \mathrm{~km}$ west of San Francisco. However, none of the WRFGFS members were able to simulate substantial clouds near the observed lightning strike locations between 1800-1900 UTC (marked with red crosses). In 
Figure 17, cloud fractions from the WRF-NAM hindcasts all contain swaths of cloudiness off the northwestern California coast as well. In fact, all the WRF-NAM hindcasts display varying amounts of cloudiness ranging from isolated cloud bands in N1 to more widespread in N3-N5 in the region of the lightning strike observations. Hindcasts N2, N3, and N5 all produced the heaviest concentrations of clouds in the desired vicinity.

Next, we will check to see how much of this cloudiness could be associated with deeper convection and thus, cloud electrification. By comparing simulated composite reflectivity from the WRF simulations at the time of the event, we can see that reflectivity from the WRF-GFS simulations became steadily more widespread in northern California in simulations with initialization closer to the actual event time (Fig. 18). However, none of the WRF-GFS simulations produced convection in the Monterey region. We speculate that the high pressure to the south was a more dominant feature in the GFS model. Two of the WRF-NAM simulations (Fig. 19) predicted convection in the Monterey Bay region as well as in northern California. Hindcast N2 indicated some isolated reflectivity in the region with low intensity (10-15 dBZ), but N3 and N5 generated more widespread reflectivity of higher intensity (25-30 dBZ) around the location of lightning strikes. It should also be noted that hindcasts N3 and N5 were both initialized from 1200 UTC forecast cycles. This could indicate that a bias from data ingestion sources (satellite retrievals, radiosondes, etc.) may be present with these particular forecast cycles and not in others. All simulations generate 
clouds in the northwestern corner of the domain, G3-G5 show deep convection north of San Francisco, and N2, N3, and N5 get convection south of San Francisco. In all WRF-GFS and WRF-NAM cases, convection is aligned southwest to northeast through the domain as the storm passes through. This matches the observations presented in Figure 3.

In comparing the hindcasts from the two sets of simulations, it is evident that WRF-GFS hindcasts were less accurate in forecasting the southern branch of this outbreak. It is worth noting, however, that the WRF-GFS hindcast members exhibited an increasing trend of convection toward the south. WRFNAM hindcasts initialized as early as 42 hours in advance of the outbreak (N2) hinted at an instability source near Monterey that fueled an increase in intensity in both cloud cover and reflectivity. Hereafter, we will focus on hindcasts N3 and N5 to understand why they succeeded while others failed. Hindcast N5 was more aggressive in generating convection across much of the domain, whereas hindcast N3 contained two distinct clusters of convection, one in northern California and a second in the Monterey region. Compared to observations (Figure 2), this was the most accurate simulation. 

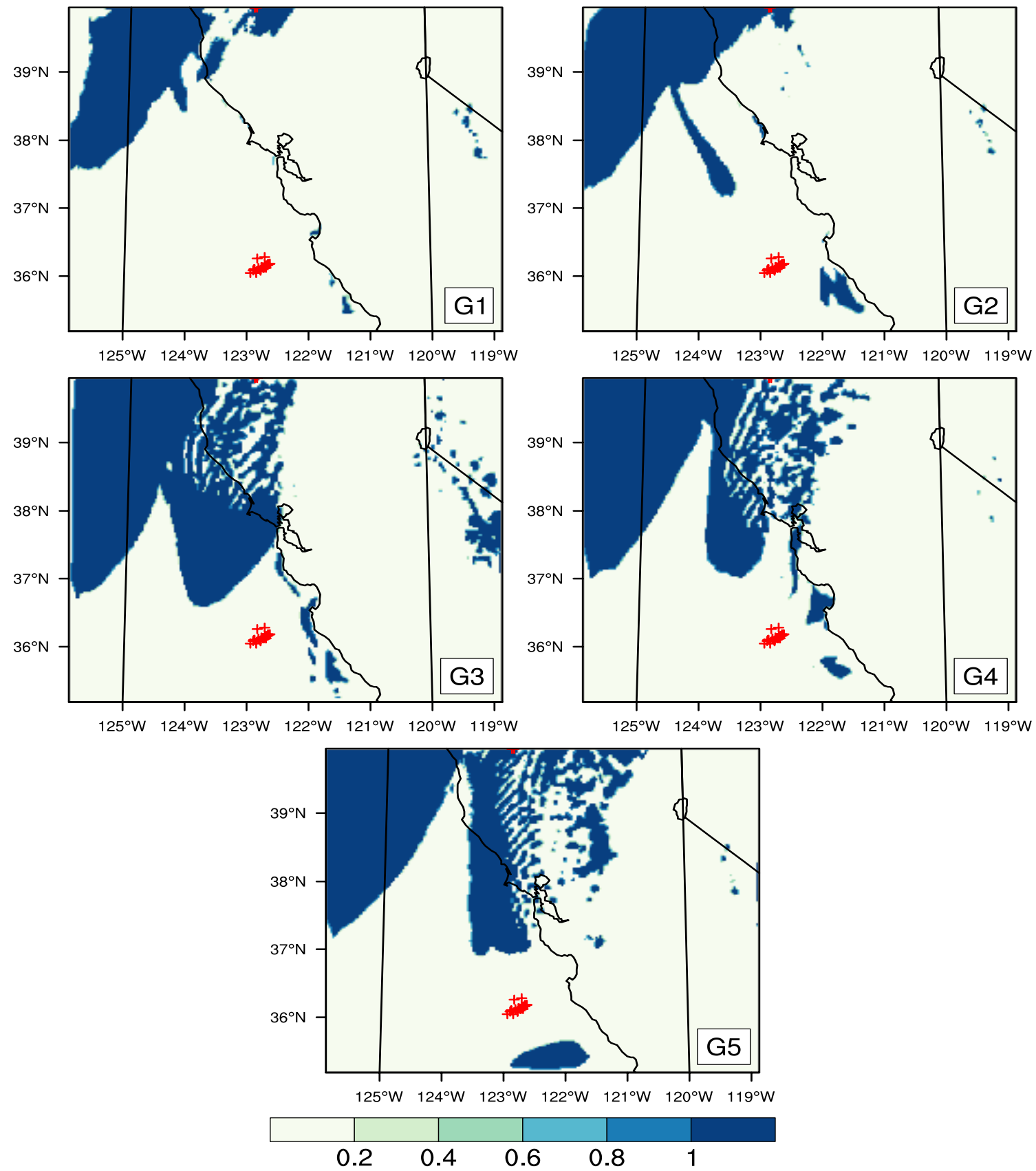

Fig. 16: Maximum simulated column cloud fraction in the WRF-GFS hindcasts valid 21 June 2008 at 1900 UTC. Red tick marks indicate observed lightning strikes between 1800 1900 UTC. 

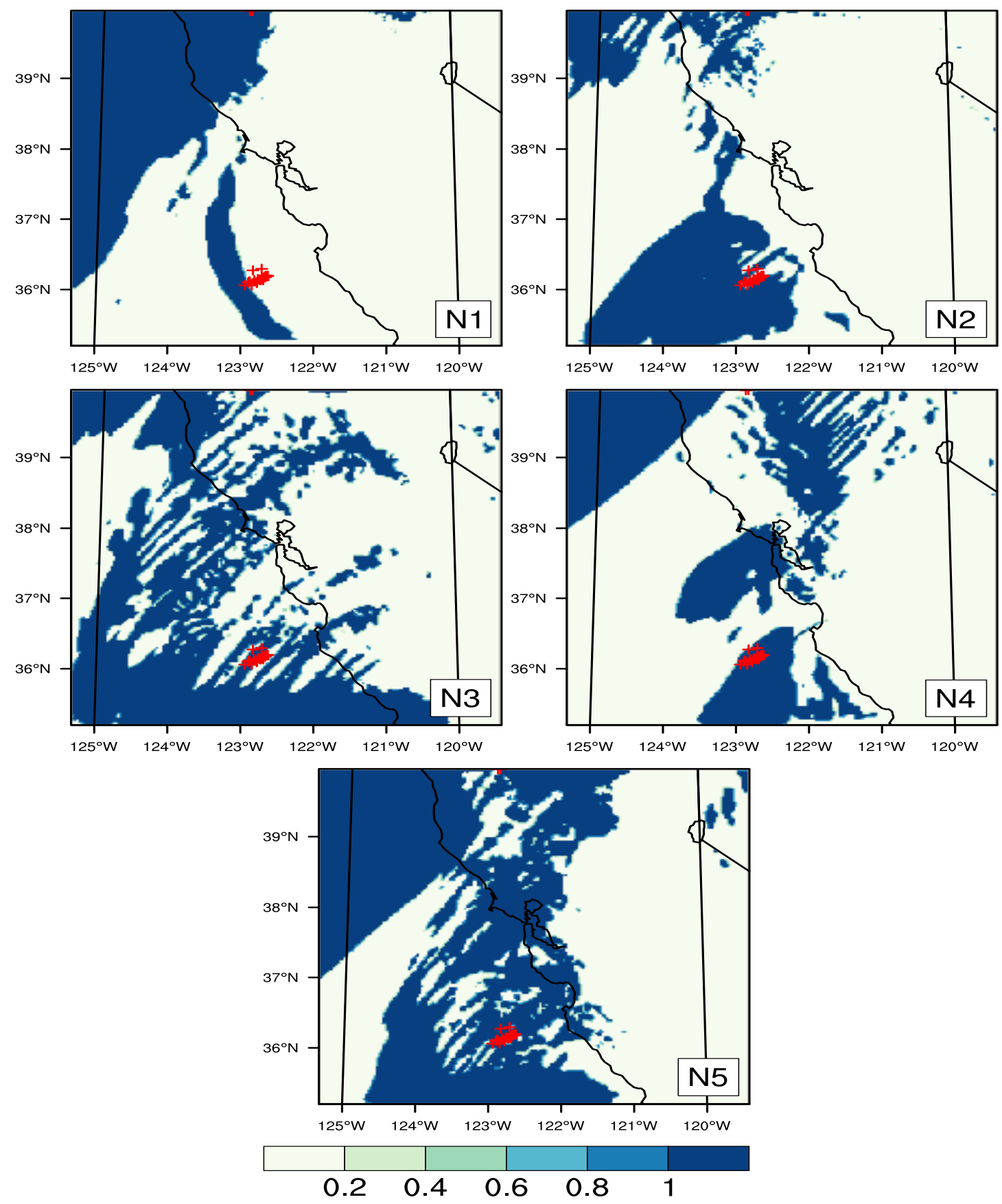

Fig. 17: Maximum simulated column cloud fraction in the WRF-NAM hindcasts valid 21 June 2008 at 1900 UTC. Red tick marks indicate observed lightning strikes between 1800 1900 UTC. 

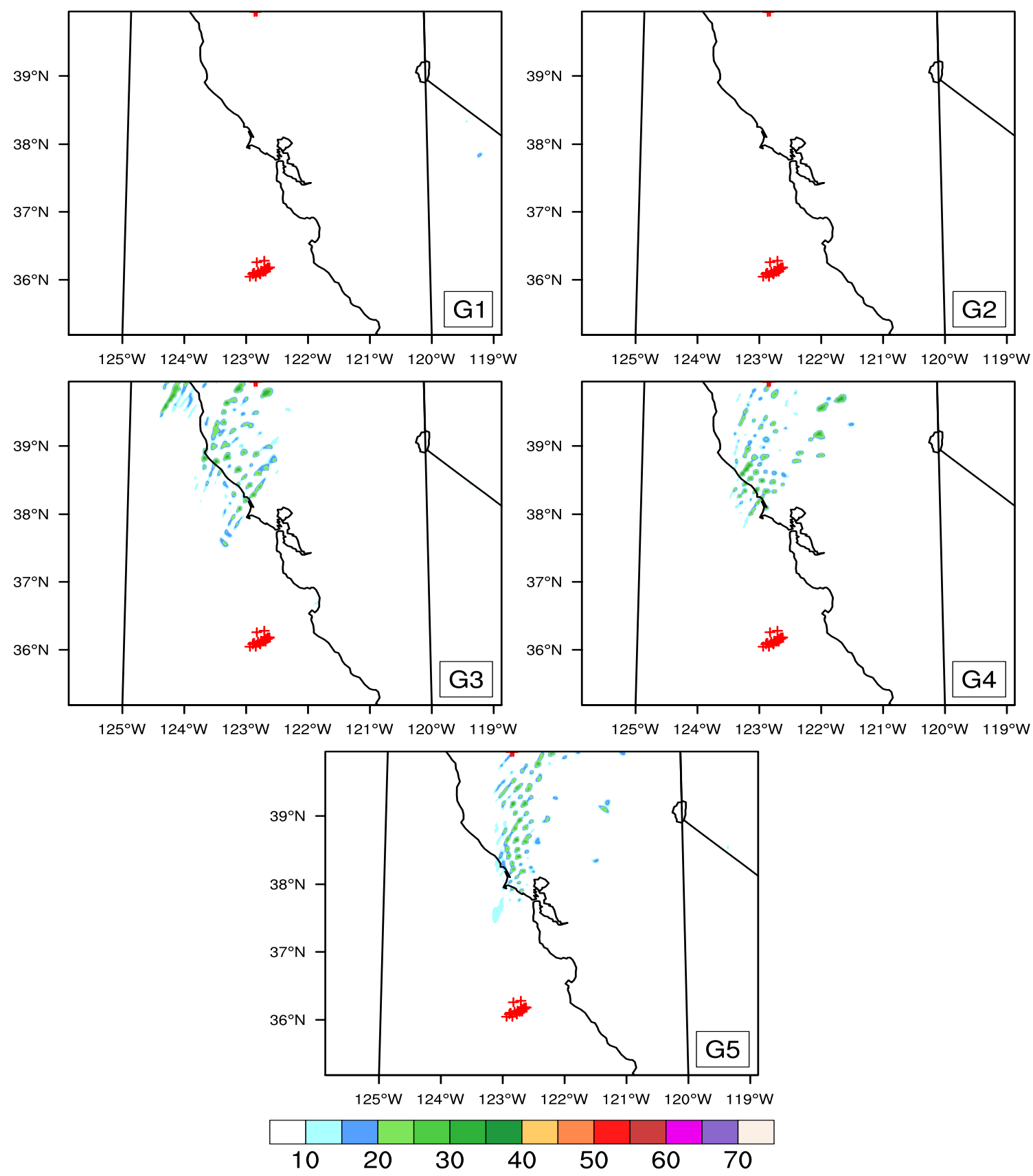

Fig. 18: Maximum simulated reflectivity (mdBZ) in WRF-GFS hindcasts valid 21 June 2008 at 1900 UTC. Red tick marks indicate lightning strike observations from $1800-1900$ UTC. 

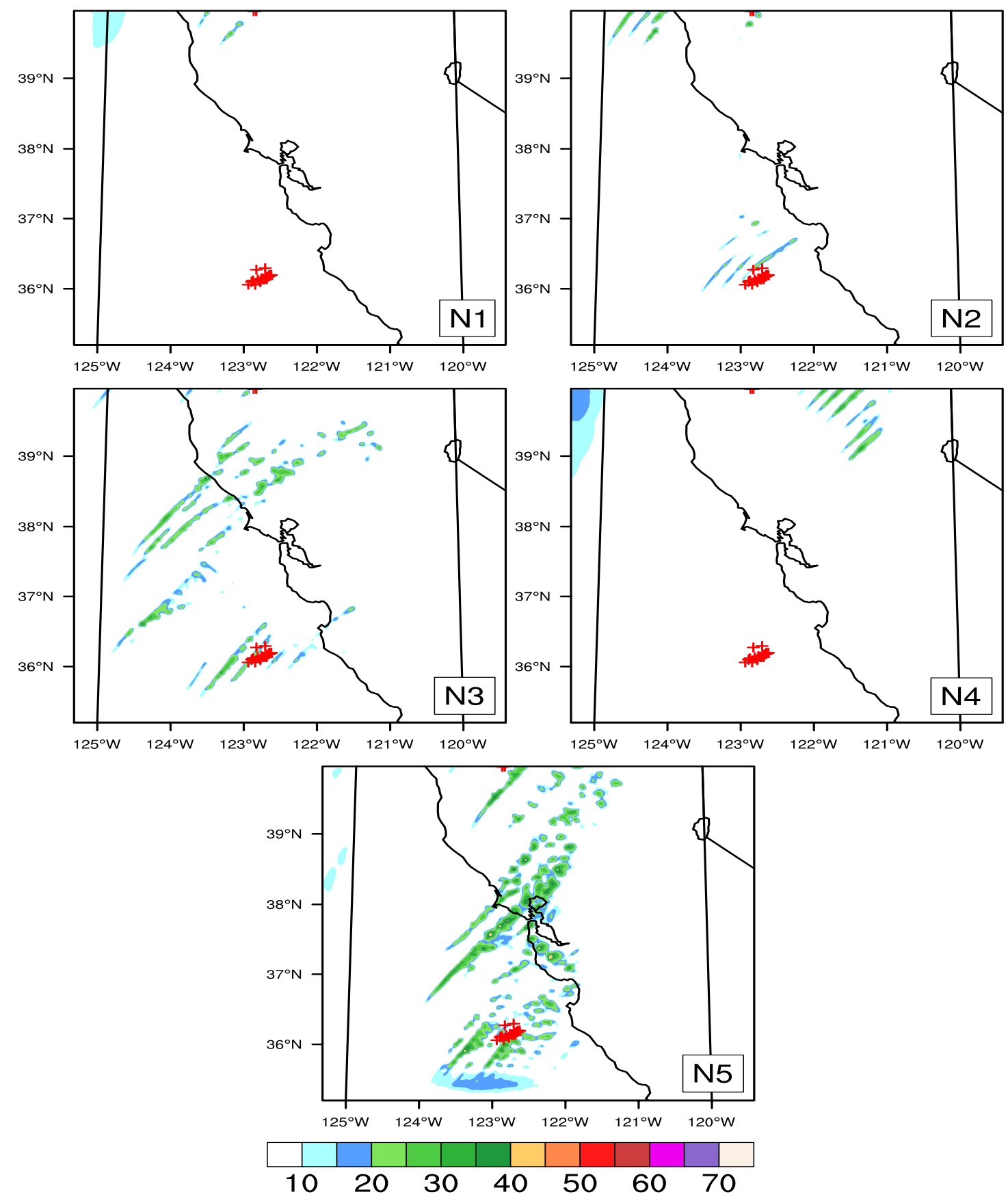

Fig. 19: Maximum simulated reflectivity (mdBZ) in WRF-NAM hindcasts valid 21 June 2008 at 1900 UTC. Red tick marks indicate lightning strike observations from $1800-1900$ UTC. 


\section{b. Analysis}

To better understand how the atmosphere evolved in the simulations, temperature and dew point profiles from model forecasts are compared with the Oakland, CA (OAK) 0000 UTC and 1200 UTC soundings from 21 June 2008. In Figure 20 the 0000 UTC profile for OAK (solid lines) shows that the atmosphere is fairly well mixed below $700 \mathrm{hPa}$ the night before the event; however, the $\mathrm{N} 1$ simulation indicated lower dew points throughout the profile suggesting less moisture present. Temperatures generally coincided with the OAK sounding data well except at the surface where temperatures were forecast consistently $5^{\circ} \mathrm{C}$ cooler than the observations. The N3 hindcast had dew points consistently about $5{ }^{\circ} \mathrm{C}$ higher than the sounding throughout much of the atmosphere, whereas the N4 simulation was too dry near the surface and too moist from $900-600 \mathrm{hPa}$.

The temperature profiles from the 1200 UTC model forecasts correspond very well with the OAK 1200 UTC sounding in Figure 21. The OAK sounding indicates two relatively moist layers between $900-800 \mathrm{hPa}$ and $700-500 \mathrm{hPa}$. The $\mathrm{N} 3$ simulation contains a relative moist layer from the surface to $850 \mathrm{hPa}$ and a deep moist layer from $700-300 \mathrm{hPa}$. All other hindcasts are drier, especially above about $500 \mathrm{hPa}$. Thus, deep moisture was present in the column only in hindcast N3.

There are many factors that can affect the simulation of moisture in a mesoscale model. This is evident from results in Figure 22 where model vapor mixing ratio profiles from each WRF-NAM simulation were sampled about $50 \mathrm{~km}$ 
offshore from Monterey. The simulated profiles vary considerably, especially around $700 \mathrm{hPa}$. There are two distinct features that likely contributed to the generation of dry convection in the southern region of the domain. The first feature is an elevated moist layer between $600-500 \mathrm{hPa}$ in all simulations near the time of convective initiation. The second notable feature is a much drier layer in N3 and N5 directly beneath the elevated moist layer with vapor mixing ratios less than $2 \mathrm{~g} \mathrm{~kg}^{-1}$. The other simulations had vapor mixing ratios that ranged between $3-6 \mathrm{~g} \mathrm{~kg}^{-1}$ in this layer.

Convective Available Potential Energy (CAPE) is a measure of instability in the atmosphere. It is the energy responsible for the acceleration an air parcel experiences due to its buoyancy between the Level of Free Convection (LFC) and the Equilibrium Level. Ambient temperature and parcel temperature are the only variables needed to calculate CAPE of parcels from a given level. While moisture is not directly incorporated into the equation to calculate CAPE, its presence or lack thereof in air parcels originating in a given layer can have significant impacts on the potential energy a parcel can access. Moisture does, however, affect the height of the Lifted Condensation Level (LCL), above which the parcel becomes saturated and its temperature will decrease according to the moist adiabatic lapse rate as it ascends. If we assume a parcel at a given level remains at a constant temperature and moisture is added to this layer (dew point increases), we would expect the LCL height to lower and the LCL temperature to increase. Parcels in an elevated layer will have LCL and LFC heights close 
together, which means that little forcing will be necessary for these parcels to become positively buoyant.
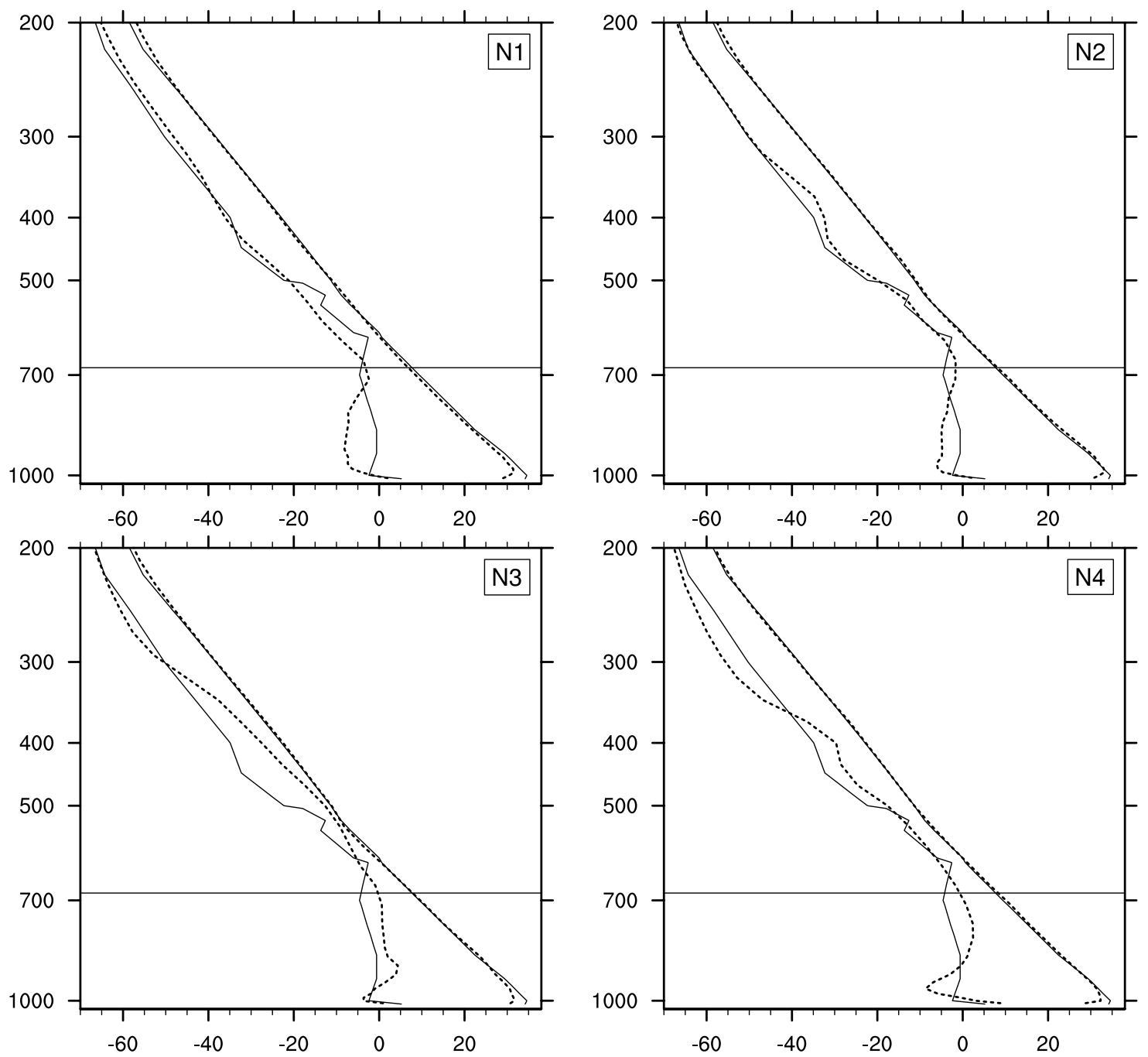

Fig. 20: Temperature and dew point temperature profiles from WRF-NAM simulations (dashed) compared with OAK sounding (solid) valid 21 June 2008 at 0000 UTC. N5 had not yet been initiated at this time. 

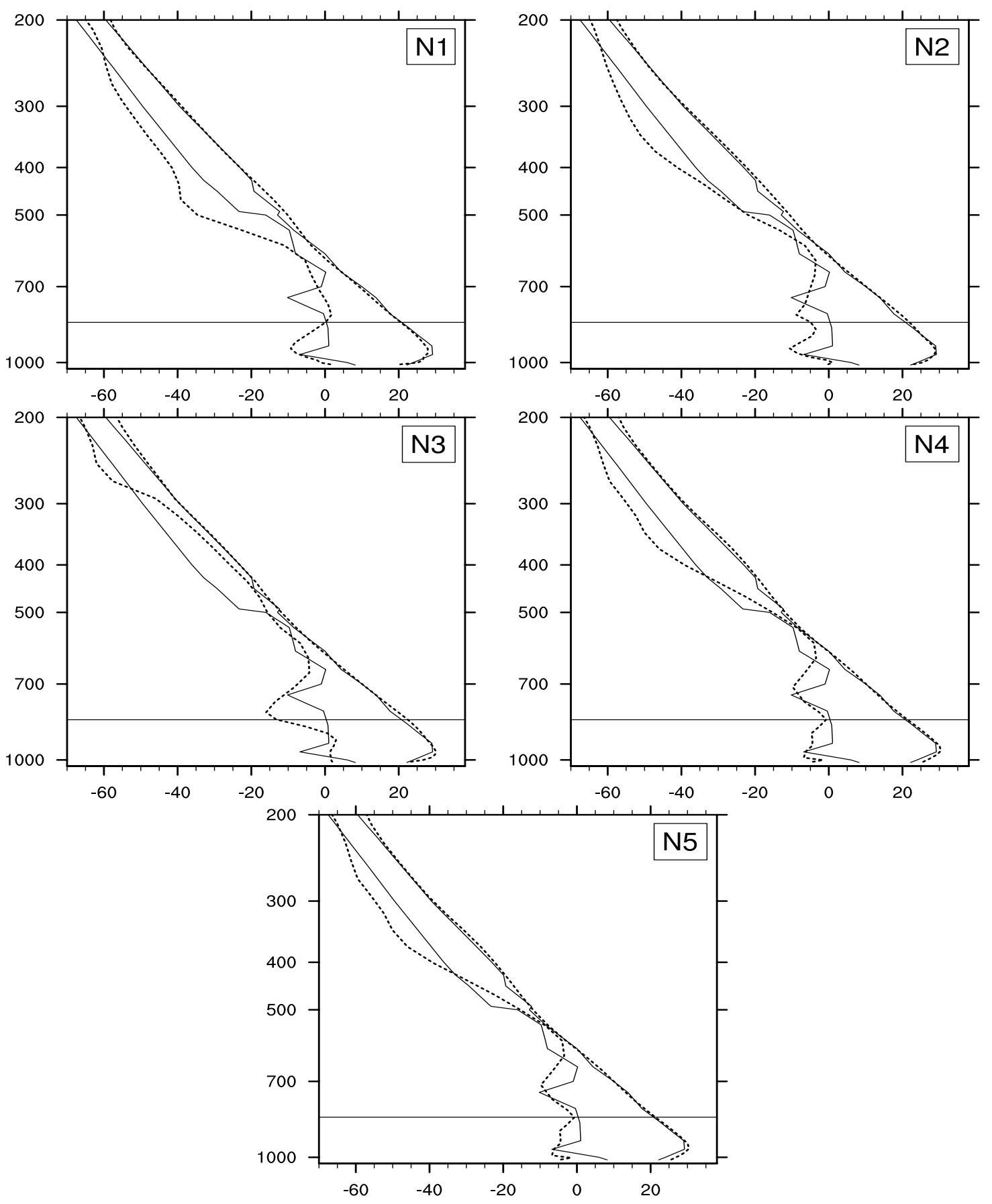

Fig. 21: Temperature and dew point temperature profiles from WRF-NAM simulations (dashed) compared with OAK sounding (solid) valid 21 June 2008 at 1200 UTC. 


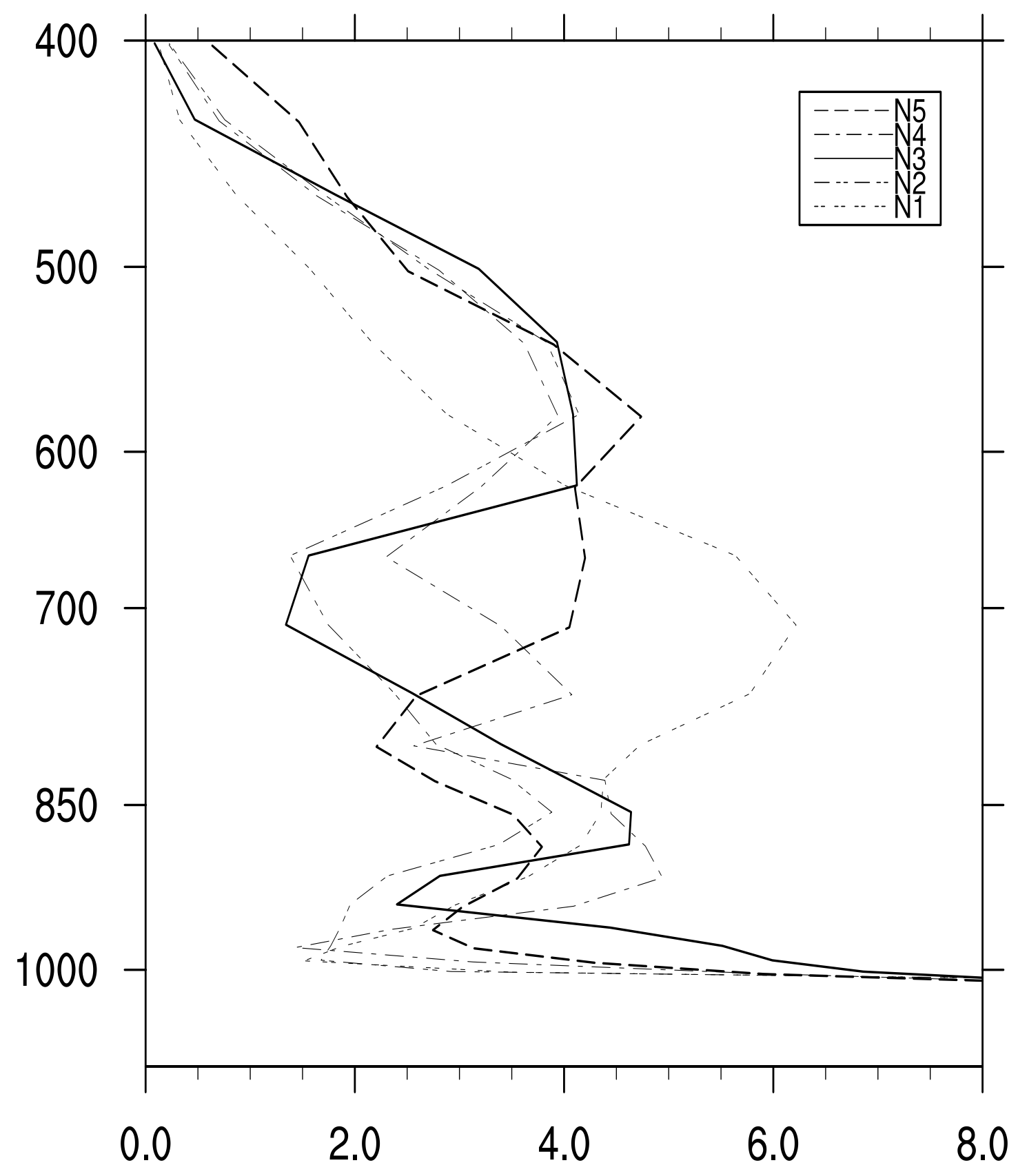

Fig. 22: Simulated vapor mixing ratio $\left(\mathrm{g} \mathrm{kg}^{-1}\right)$ profile from a point roughly $125 \mathrm{~km}$ offshore from Monterey $\left(36^{\circ} \mathrm{N}, 123^{\circ} \mathrm{W}\right)$ from WRF-NAM simulations valid 21 June 2008 at 1800 UTC, in the region where lightning strikes were observed. Bold lines indicate WRF-NAM simulations that generated convection near Monterey. 
The spatial distribution of CAPE at vertical level 16 (roughly $4.5 \mathrm{~km} \mathrm{AGL)}$ is shown in Figure 23. Both the N3 and N5 hindcasts include a source region for instability along the southern edge of the domain (between $123-124^{\circ} \mathrm{W}$ ). N3 has CAPE values of $200-250 \mathrm{~J} \mathrm{~kg}^{-1}$ at this time, while N5 had values greater than $500 \mathrm{~J} \mathrm{~kg}^{-1}$. These CAPE values are modest in comparison with those of severe weather outbreaks in the central and southeast regions of the US, where surface-based instability often increases well above $1000 \mathrm{~J} \mathrm{~kg}^{-1}$. However, values near $500 \mathrm{~J} \mathrm{~kg}^{-1}$ are more typical of elevated dry convection in northern California (Wallman et al. 2010; Nauslar et al. 2013). Our conclusion is that $200-500 \mathrm{~J} \mathrm{~kg}^{-1}$ is sufficient for elevated convection outbreaks on the west coast. Thus we see that of the 10 hindcasts, only 2 (N3 and N5) featured values of CAPE/MUCAPE likely to support convection and lightning.

One clear difference between the five WRF-NAM simulations was the model moisture profiles. Cross sections of vapor mixing ratio and CAPE indicate several features unique to the N3 simulation (Fig. 24). Here, the CAPE values at each vertical level represent the combined buoyancy of only the levels above it. The greatest instability coincides with regions in the domain where mixing ratios exceed $4.5-5 \mathrm{~g} \mathrm{~kg}^{-1}$ above the inversion. In the N3 hindcast, high values are confined to a relatively shallow layer between 4-5 km AGL. The cross sections confirm that surface-based CAPE was not present, even in the N3 hindcast where boundary layer mixing ratios exceeded $4.5 \mathrm{~g} \mathrm{~kg}^{-1}$ (another feature absent from other hindcasts). All GFS hindcast cross sections (not shown) share the 
mostly dry conditions in the boundary layer common in the NAM hindcasts. Just above the boundary layer in the GFS hindcasts, there are two moist layers separated by a layer of drier air. The bulk of the moisture in these hindcasts is contained below $4 \mathrm{~km} \mathrm{AGL}$ with mixing ratios of more than $6 \mathrm{~g} \mathrm{~kg}^{-1}$, which is greater than the NAM hindcasts. Two GFS simulations (G2 and G4 hindcasts) had thin layers of elevated CAPE around $4 \mathrm{~km} \mathrm{AGL}$ within the lofted moist layer.

Upper level lapse rates were analyzed in our simulations to determine upper level instability, as suggested by Wallman et al. (2010) and Nauslar et al. (2013). In Figure 25, the $500-300 \mathrm{hPa}$ lapse rate was calculated for each grid point in the simulation domain. The upper level instability in each hindcast showed a great deal of variance. The $\mathrm{N} 1$ hindcast had lapse rates greater than the $7.5^{\circ} \mathrm{C} \mathrm{km}^{-1}$ threshold across much of the domain throughout the day on 21 June 2008. The N2 hindcast lapse rates decreased near the Monterey lightning complex from 7.2 to below $7.0^{\circ} \mathrm{C} \mathrm{km}^{-1}$ between $1200-1700$ UTC and then increased to $7.3^{\circ} \mathrm{C} \mathrm{km}^{-1}$ after 1800 UTC. In N3, lapse rates in the Monterey Bay region were $7.2^{\circ} \mathrm{C} \mathrm{km}^{-1}$ at 1200 UTC. By 1400 UTC, several bands of higher lapse rates of $7.4{ }^{\circ} \mathrm{C} \mathrm{km}^{-1}$ formed in this region and one or two bands achieved the $7.5^{\circ} \mathrm{C} \mathrm{km}^{-1}$ threshold by 1900 UTC. This threshold was determined by operational experience from Wallman et al. (2010) to provide enough instability for dry thunderstorm development. Lapse rates above $7.5^{\circ} \mathrm{C} \mathrm{km}^{-1}$ were also found throughout the day in northern California in this simulation. In hindcast N4, lapse rates generally decreased throughout the day in much of the domain with 
values in the Monterey region decreasing from 7.2 to $7.0^{\circ} \mathrm{C} \mathrm{km}^{-1}$. Hindcast N5 showed rapid destabilization of the upper atmosphere in the Monterey Bay region. From 1200 - 1600 UTC, lapse rates decreased just slightly from 7.1 to $7.0{ }^{\circ} \mathrm{C} \mathrm{km}^{-1}$ then increased to over $8.0^{\circ} \mathrm{C} \mathrm{km}^{-1}$ after $1600 \mathrm{UTC}$ in the region of interest, as well as a considerable portion of the domain to the north.

These results pose intriguing questions about the influence of upper level lapse rates. In the hindcasts where convection occurred near Monterey, the lapse rates were $0.3-0.4{ }^{\circ} \mathrm{C} \mathrm{km}^{-1}$ lower than the threshold of $7.5^{\circ} \mathrm{C} \mathrm{km}^{-1}$ until the time period when convection initiated in the simulations. So, does the dry convection begin as soon as the threshold is crossed, provided that adequate moisture is in place? Or does the dry convection modify the upper level environment to promote additional destabilization? Our simulations were not recorded at a high enough temporal resolution to provide a detailed answer, but this could be examined in the future. 

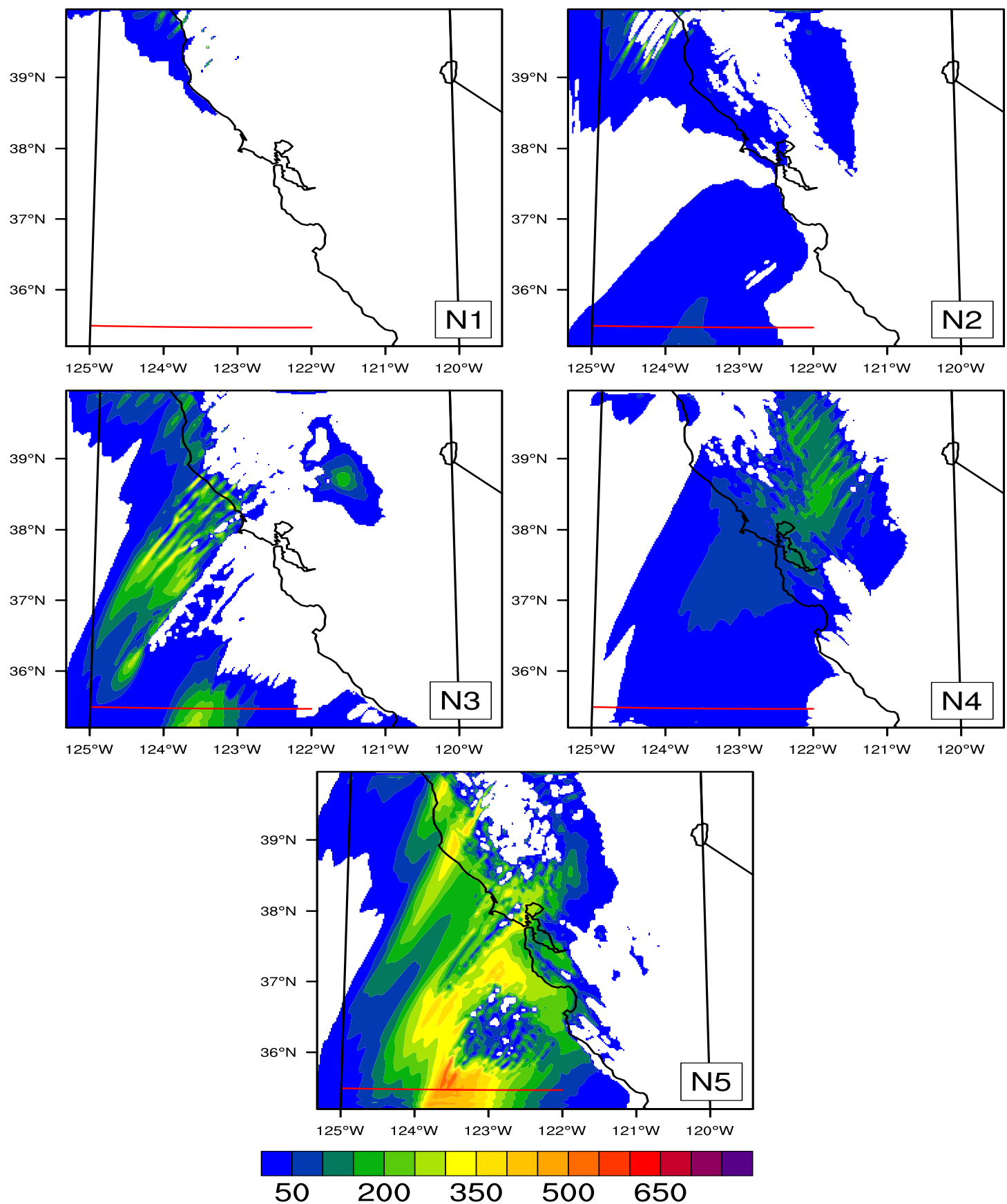

Fig. 23: Simulated CAPE $\left(\mathrm{J} \mathrm{kg}^{-1}\right)$ along the $16^{\text {th }}$ vertical level from WRF-NAM hindcasts valid 21 June 2008 at 1800 UTC. This vertical level corresponds roughly to the $650 \mathrm{hPa}$ level in the model. Red line indicates transect location for Figure 24. 

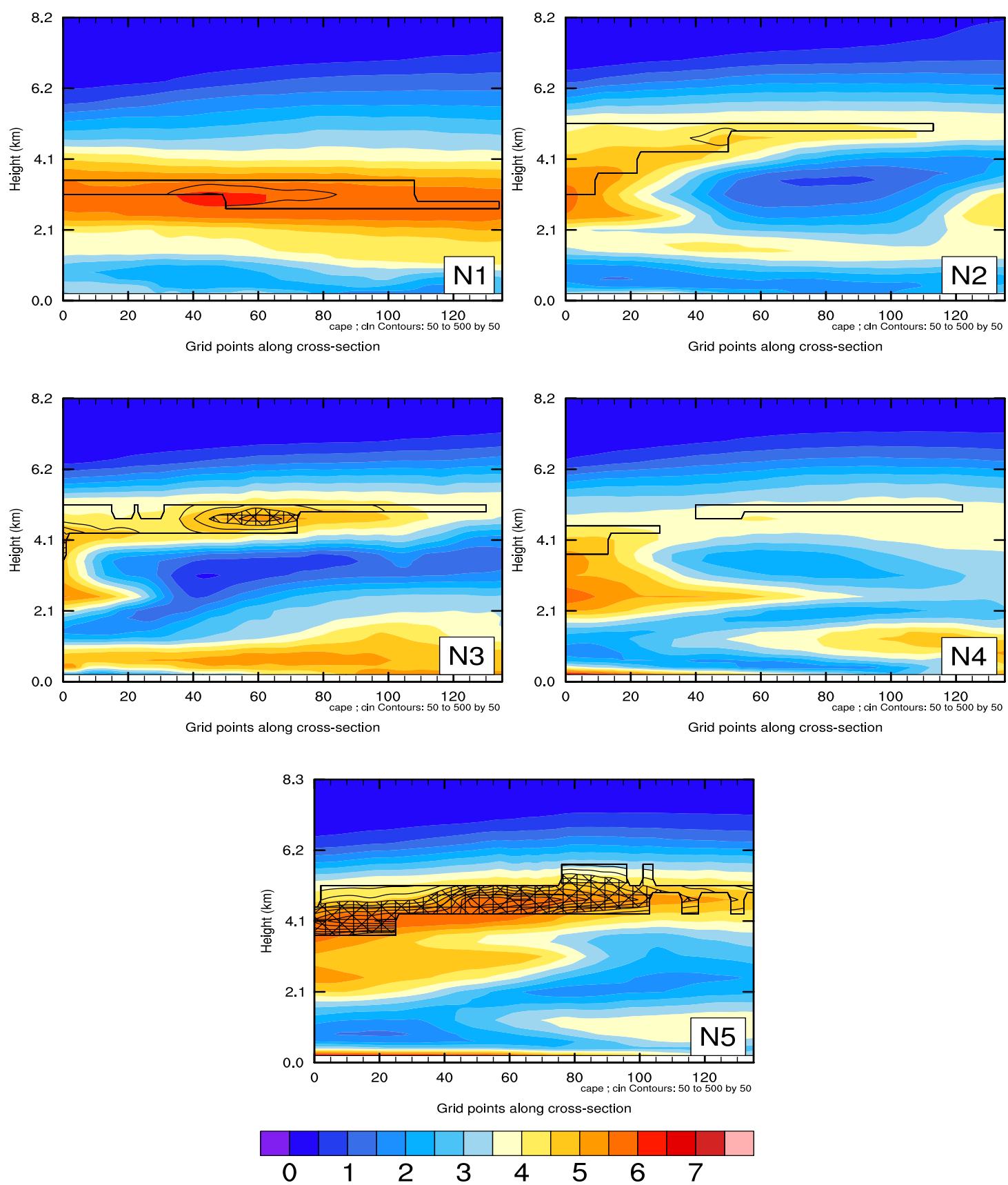

Fig. 24: Vertical cross-sections from WRF-NAM hindcasts of simulated CAPE (black contours, $\mathrm{J} \mathrm{kg}^{-1}$ ) and vapor mixing ratio (color fill, $\mathrm{g} \mathrm{kg}^{-1}$ ) valid 21 June 2008 at 1800 UTC. Crosshatch indicates CAPE values that exceed $200 \mathrm{~J} \mathrm{~kg}^{-1}$. Transect location is indicated by red lines in Figure 23. 

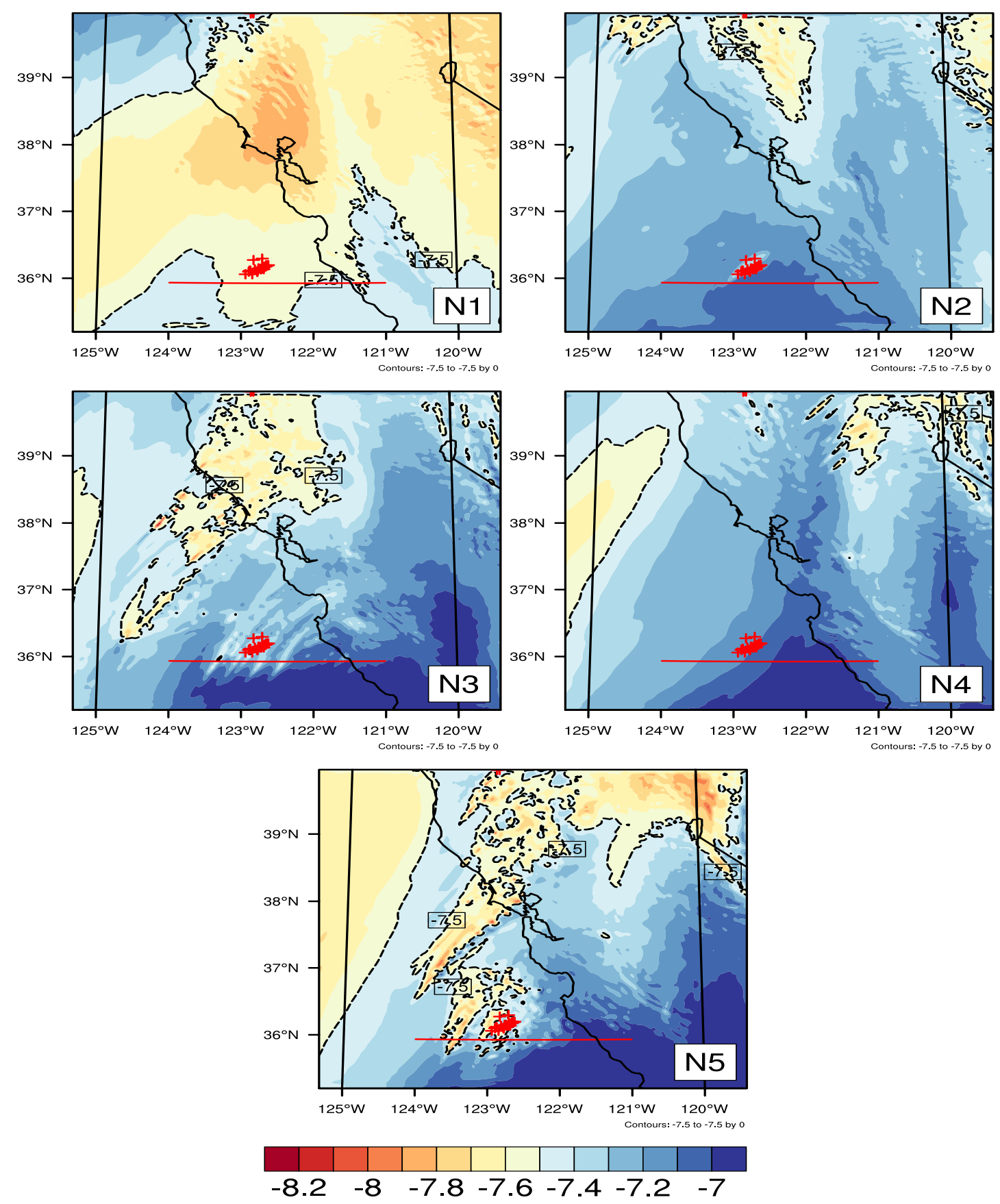

Fig. 25: Simulated upper level lapse rates $\left(\mathrm{T}_{500}-\mathrm{T}_{300},{ }^{\circ} \mathrm{C} \mathrm{km}{ }^{-1}\right)$ from WRF-NAM hindcasts valid 21 June 2001 at 1800 UTC. Dashed line indicates the $7.5^{\circ} \mathrm{C} \mathrm{km}^{-1}$ threshold found to be useful in forecasting dry lightning, according to Nauslar et al. (2013). Red lines indicate transect locations for Figures 26-29. 
By investigating vertical cross-sections of relative humidity $(\mathrm{RH})$, we can pinpoint layers where clouds are likely to form given adequate cloud condensation nuclei. From Figure 26, we see that the $\mathrm{RH}$ in the $\mathrm{N} 1$ simulation at 1800 UTC is significantly lower than all other simulations, seldom reaching above 50 percent throughout the cross-section indicated by the red line in Figure 25.

The remaining runs contain humid layers between $4-6 \mathrm{~km}$ AGL, where humidity reaches over 80 percent. $\mathrm{RH}$ in the $\mathrm{N} 4$ simulation steadily decreases over time, whereas the N2 simulation maintains humidity of at least 80 percent within the layer. The N3 and N5 runs were the only simulations to contain convective elements associated with the humid layer, as denoted by vertical velocities of roughly $\pm 70 \mathrm{~cm} \mathrm{~s}^{-1}$. The vertical velocity magnitude intensified in N3 and N5 one hour later and with cloud top heights greater than 8 km AGL (Fig. 27).

So far, we have established that some of the WRF simulations were successful in forecasting dry convection in the Monterey region around the same time lightning strikes were detected. The final goal of this research is to identify methods to forecast lightning from WRF output, and determine their usefulness in conditions favorable for dry lightning. The presence of graupel inside storm clouds has been linked with cloud electrification (Bruning et al. 2012; MacGorman et al. 2007; and Saunders 2008). Several microphysics schemes in WRF allow calculations of graupel mixing ratio along with other ice particles. McCaul et al. (2009) devised a lightning threat detection method that only requires ice specie mixing ratios (mainly graupel) and vertical wind velocities to 
compute. It is currently incorporated as an analysis product of the High Resolution Rapid Refresh (HRRR) model. The group's analysis technique consists of two blended parts. One part of the equation assesses the magnitude of the lightning threat based on the graupel flux through the $-15^{\circ} \mathrm{C}$ isotherm, and is weighted at $95 \%$. The second part assesses the spatial distribution of lightning threat as the sum of the vertical integration of the ice, snow, and graupel species, and is weighted at $5 \%$. The N3 and N5 NAM hindcasts were deemed most suitable for testing this algorithm.

We examined the structure of the simulated convective elements to determine if graupel was present. In Figure 28, vertical cross-sections of graupel mixing ratio and vertical velocity are analyzed around the time of the first Monterey lightning strike observations (1800 UTC). By this time, the N3 and N5 hindcasts had already generated moderate convection in the region with cloud bases above $4 \mathrm{~km}$ (established in Figure 26). The convective elements in hindcast N3 contained updrafts above $25 \mathrm{~cm} \mathrm{~s}^{-1}$, but this was not vigorous enough to promote graupel growth as maximum graupel mixing ratios remained below $0.05 \mathrm{~g} \mathrm{~kg}^{-1}$. The convective elements in hindcast N5, however, contained updrafts as robust as $125 \mathrm{~cm} \mathrm{~s}^{-1}$ in some locations and were roughly collocated with maximum graupel mixing ratios exceeding $0.4 \mathrm{~g} \mathrm{~kg}^{-1}$ around the $-15^{\circ} \mathrm{C}$ isotherm. Based on microphysical variables from hindcast N5, it can be inferred that cloud electrification was possible at this time. Although modest, Hindcast N3 indicated its first signs of cloud electrification one hour later in the simulation, as 
shown in Figure 29. At this time, a graupel mixing ratio maximum greater than $0.6 \mathrm{~g} \mathrm{~kg}^{-1}$ was embedded within an updraft core with a maximum velocity of 225 $\mathrm{cm} \mathrm{s}^{-1}$ at the $-15^{\circ} \mathrm{C}$ level. The convection in Hindcast N5 showed signs of strengthening as well, where updraft cores increased to over $225 \mathrm{~cm} \mathrm{~s}^{-1}$ and graupel mixing ratio maximum increased above $2 \mathrm{~g} \mathrm{~kg}^{-1}$.

Presently, lightning is not directly simulated by WRF, so proxy methods must be used to forecast lightning strike intensity. McCaul et al. (2009) compared lightning strike observations with simulated graupel flux and determined the relationship to be 0.042 flashes $\mathrm{km}^{-2} 5 \mathrm{~min}^{-1}$ for every $1 \mathrm{~g} \mathrm{~m} \mathrm{~kg}^{-1} \mathrm{~s}^{-1}$ of graupel flux through the $-15{ }^{\circ} \mathrm{C}$ isotherm based on linear regression. We estimated graupel flux at this level from the N3 and N5 hindcasts to determine its usefulness as a prediction of dry lightning. Figure 30 shows graupel flux in N3 at 1845 UTC, when convection was determined to be rigorous enough for cloud electrification. The maximum graupel flux of $1.5 \mathrm{~g} \mathrm{~m} \mathrm{~kg}^{-1} \mathrm{~s}^{-1}$ near Monterey was generally weak and at the low end $\left(<0.1\right.$ flash $\left.\mathrm{km}^{-2} 5 \mathrm{~min}^{-1}\right)$ of the lightning flash density calibration curves described by McCaul et al. (2009). Figure 31 shows graupel flux in the N5 hindcast at the same time. The maximum graupel flux of 7 $\mathrm{g} \mathrm{m} \mathrm{kg}^{-1} \mathrm{~s}^{-1}$ near Monterey, while more robust, was generally weak and still at the low end $\left(<0.3\right.$ flash $\left.\mathrm{km}^{-2} 5 \mathrm{~min}^{-1}\right)$ of the lightning flash density calibration curves. Nevertheless, the configurations used for the WRF-NAM simulations demonstrated some skill in resolving location of lightning threat based on microphysical features from this outbreak. For comparison, Newman and 
Johnson (2012) computed domain-averaged graupel mixing ratio and graupel flux associated with convection from a tropical upper tropospheric trough in the North American Monsoon region to range from $0.5-1.5 \mathrm{~g} \mathrm{~kg}^{-1}$ and $2.0-6.0 \mathrm{~g} \mathrm{~m} \mathrm{~kg}^{-1}$ $\mathrm{s}^{-1}$ respectively.

Overall, the WRF-GFS simulations all failed to predict convective activity in the Monterey Bay area, although they did predict clouds and convection in northern California. Two WRF-NAM simulations predicted instability near Monterey Bay. This agreed well with observations. All WRF-NAM simulations had an elevated moist layer, but the simulations with convection (N3 and N5) had this moist layer higher than $4 \mathrm{~km} \mathrm{AGL}$ with mixing ratios greater than $4.5 \mathrm{~g} \mathrm{~kg}^{-1}$. In this case, we speculate that the NAM initialization and boundary forcing provided more accurate moisture fields. Parcels from this layer were conditionally unstable and were able to reach the level of free convection with the aid of weak lift provided from local jet streak circulations associated with the incoming shortwave. Above the LFC, these parcels would have access to modest CAPE values of $200-500 \mathrm{~J} \mathrm{~kg}^{-1}$ with upper level lapse rates greater than $7.5^{\circ} \mathrm{C} \mathrm{km}^{-1}$. These two WRF-NAM simulations showed that cloud electrification was possible near Monterey from 1800 - 1900 UTC, due to the detection of graupel flux within the cloud's charging region. 
Relative Humidity (\%)

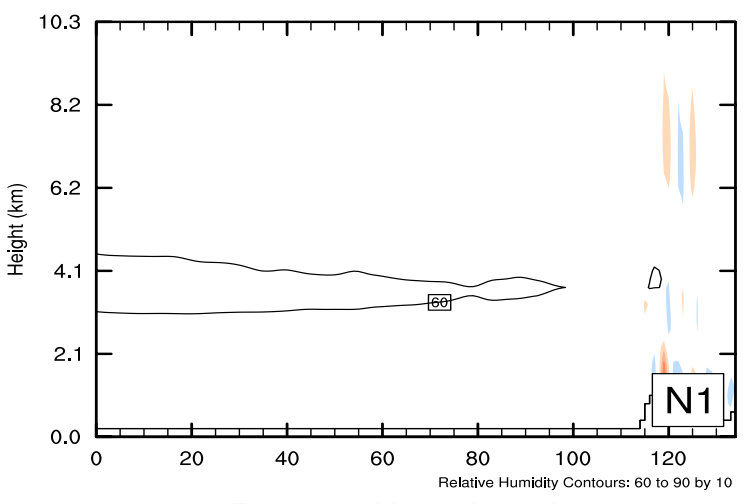

Relative Humidity (\%)

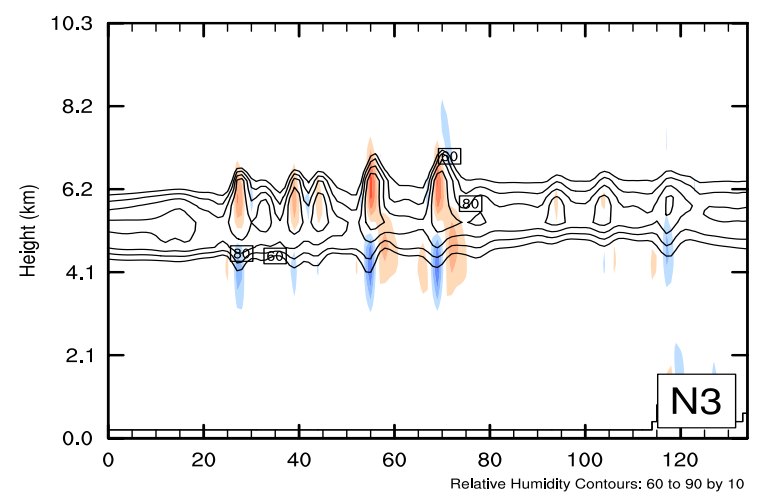

Relative Humidity
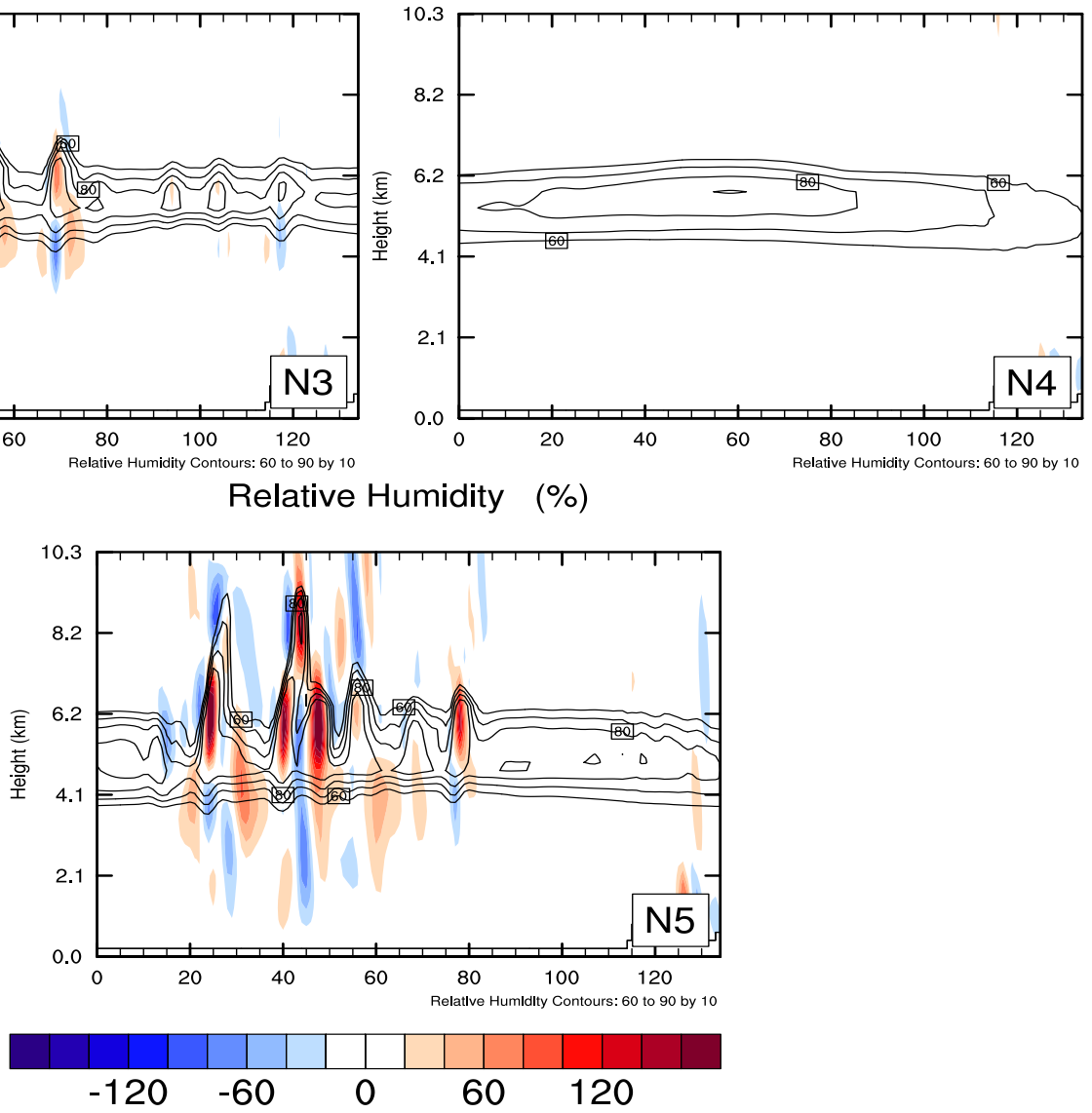

Fig. 26: Vertical cross-sections from WRF-NAM hindcasts of simulated relative humidity (contour, \%) and vertical velocity (fill, $\mathrm{cm} \mathrm{s}^{-1}$ ) valid 21 June 2008 at 1800 UTC. Red shading indicates upward vertical motion and blue shading indicates downward vertical motion. 
Relative Humidity (\%)

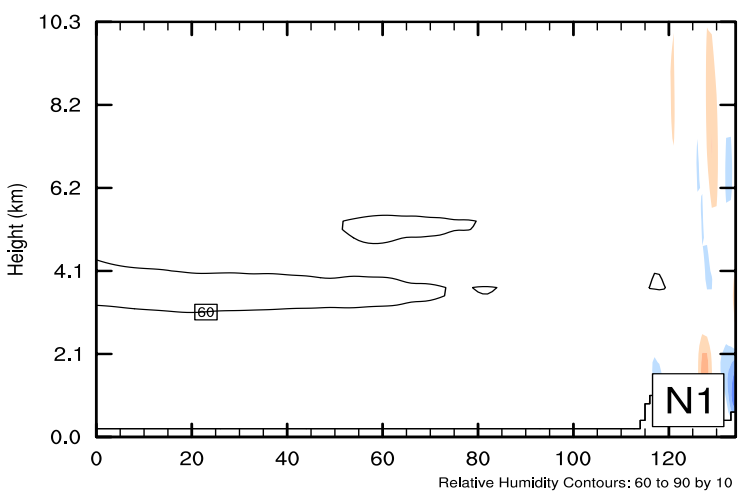

Relative Humidity (\%)

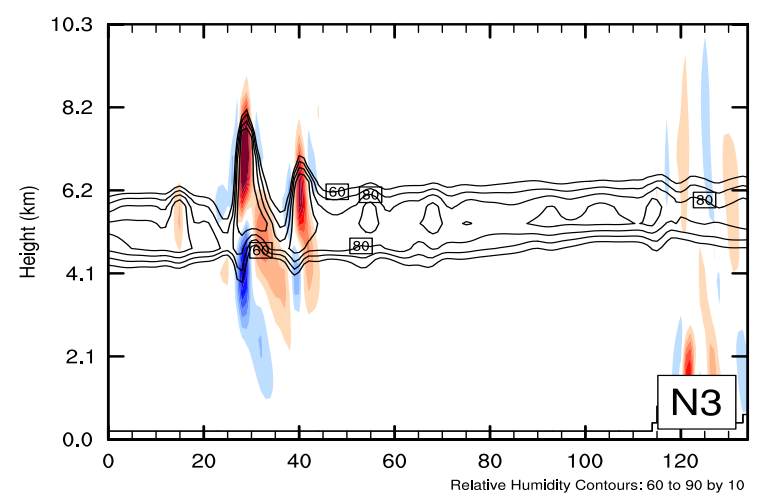

Relative Humidity (\%)

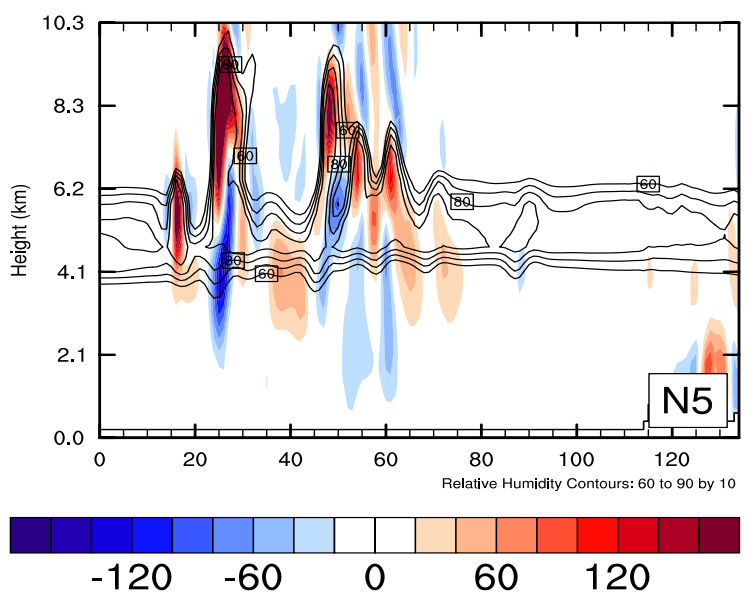

Fig. 27: Vertical cross-sections from WRF-NAM hindcasts of simulated relative humidity (contour, \%) and vertical velocity (fill, $\mathrm{cm} \mathrm{s}^{-1}$ ) valid 21 June 2008 at 1900 UTC. Red shading indicates upward vertical motion and blue shading indicates downward vertical motion. 

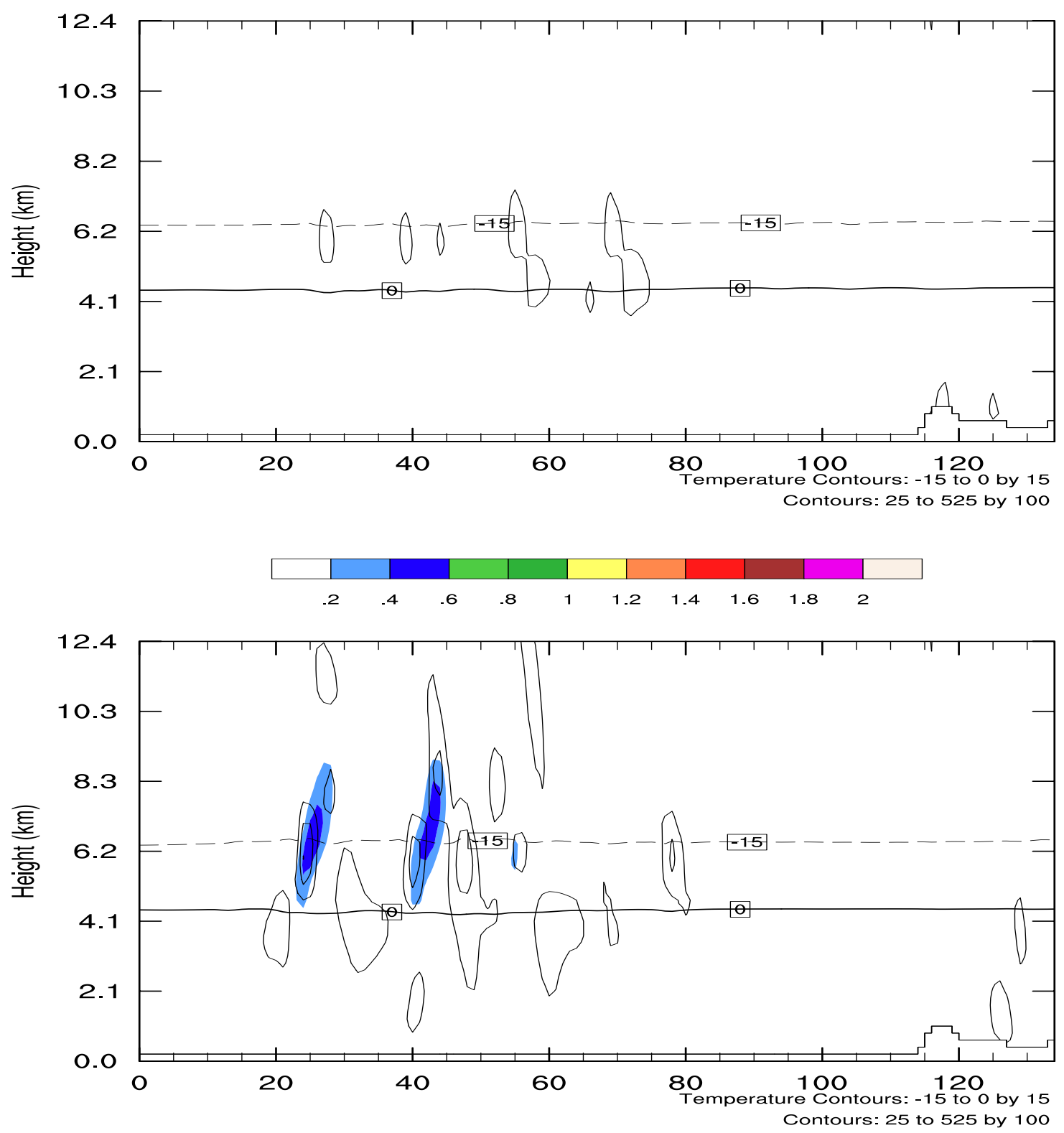

Fig. 28: Vertical cross-sections from WRF-NAM N3 (top) and N5 (bottom) simulations of positive vertical velocity (contour lines, $\mathrm{cm} \mathrm{s}^{-1}$ ) and graupel mixing ratio (color fill, $\mathrm{g} \mathrm{kg}^{-1}$ ) valid 21 June 2008 at 1800 UTC. The single dashed line is the $-15^{\circ} \mathrm{C}$ isotherm and the single bold line is the $0^{\circ} \mathrm{C}$ isotherm. 

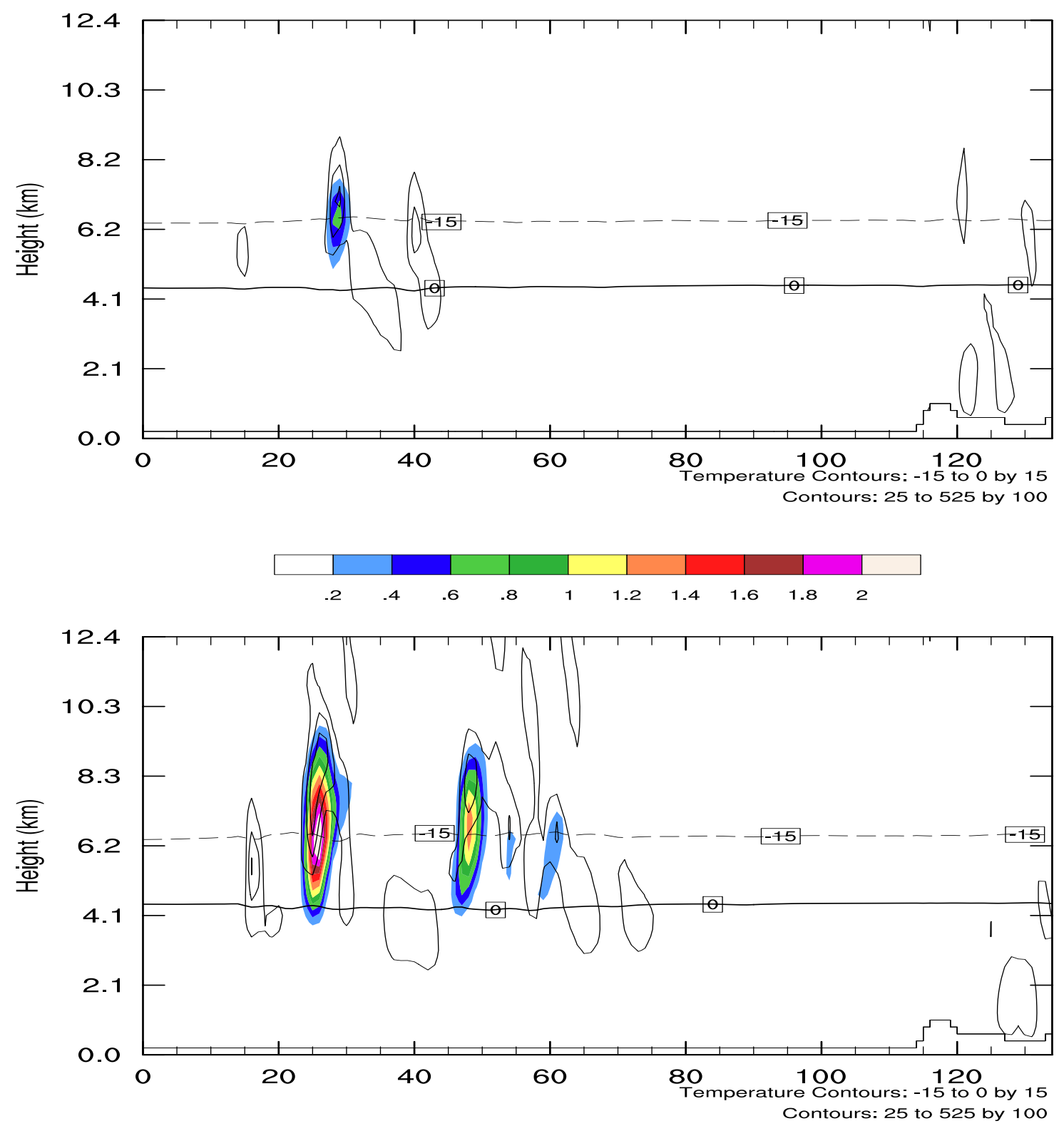

Fig. 29: Vertical cross-sections from WRF-NAM N3 (top) and N5 (bottom) simulations of positive vertical velocity (contour lines, $\mathrm{cm} \mathrm{s}^{-1}$ ) and graupel mixing ratio (color fill, $\mathrm{g} \mathrm{kg}^{-1}$ ) valid 21 June 2008 at 1900 UTC. The single dashed line is the $-15^{\circ} \mathrm{C}$ isotherm and the single bold line is the $0^{\circ} \mathrm{C}$ isotherm. 

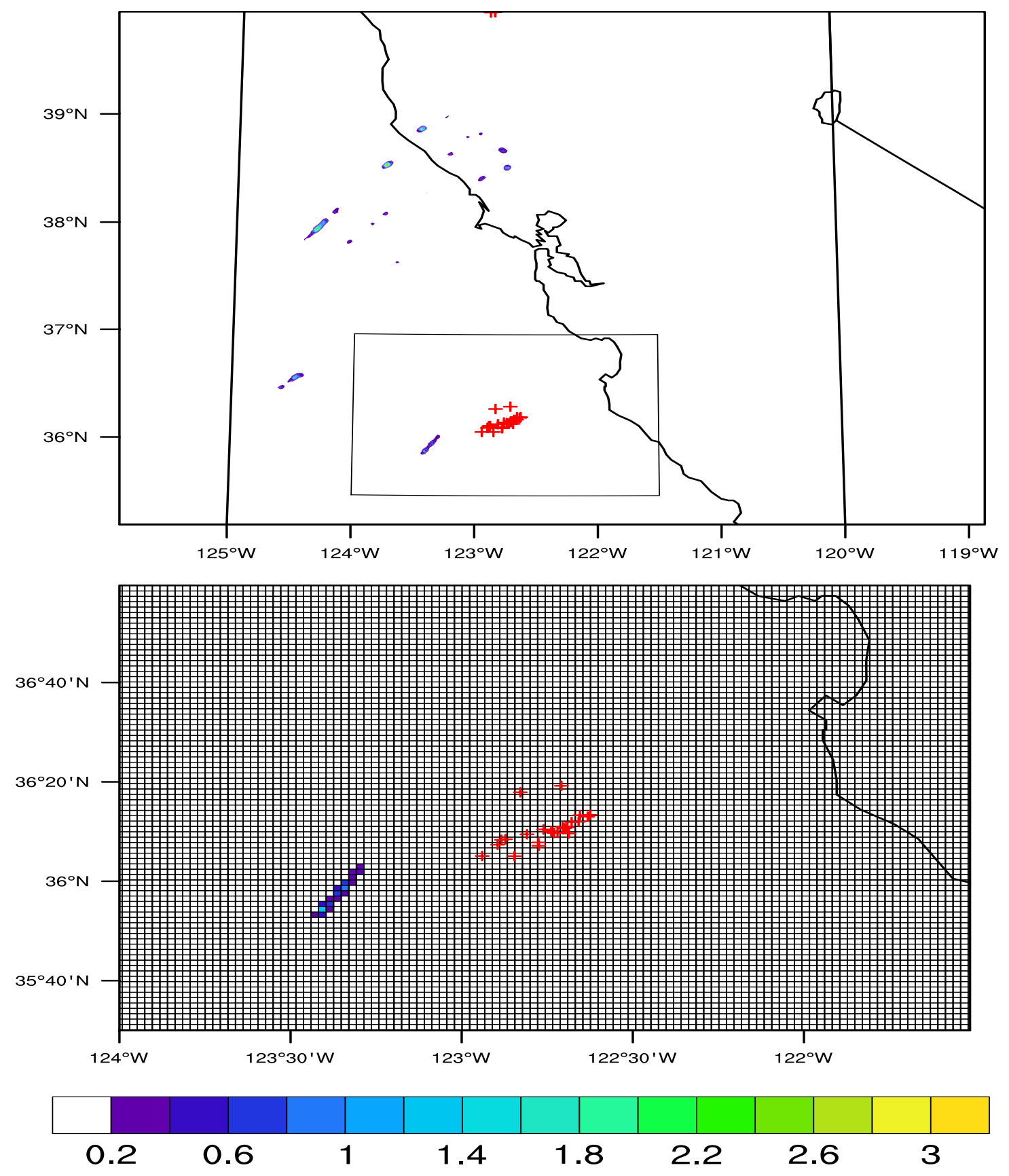

Fig. 30: Hindcast N3 simulated vertical graupel flux through the $-15^{\circ} \mathrm{C}$ isotherm (top, color fill) and zoomed in around the Monterey convective bands (bottom) to show relative size of elements in comparison to individual grid cells, valid 21 June 2008 at 1845 UTC. 

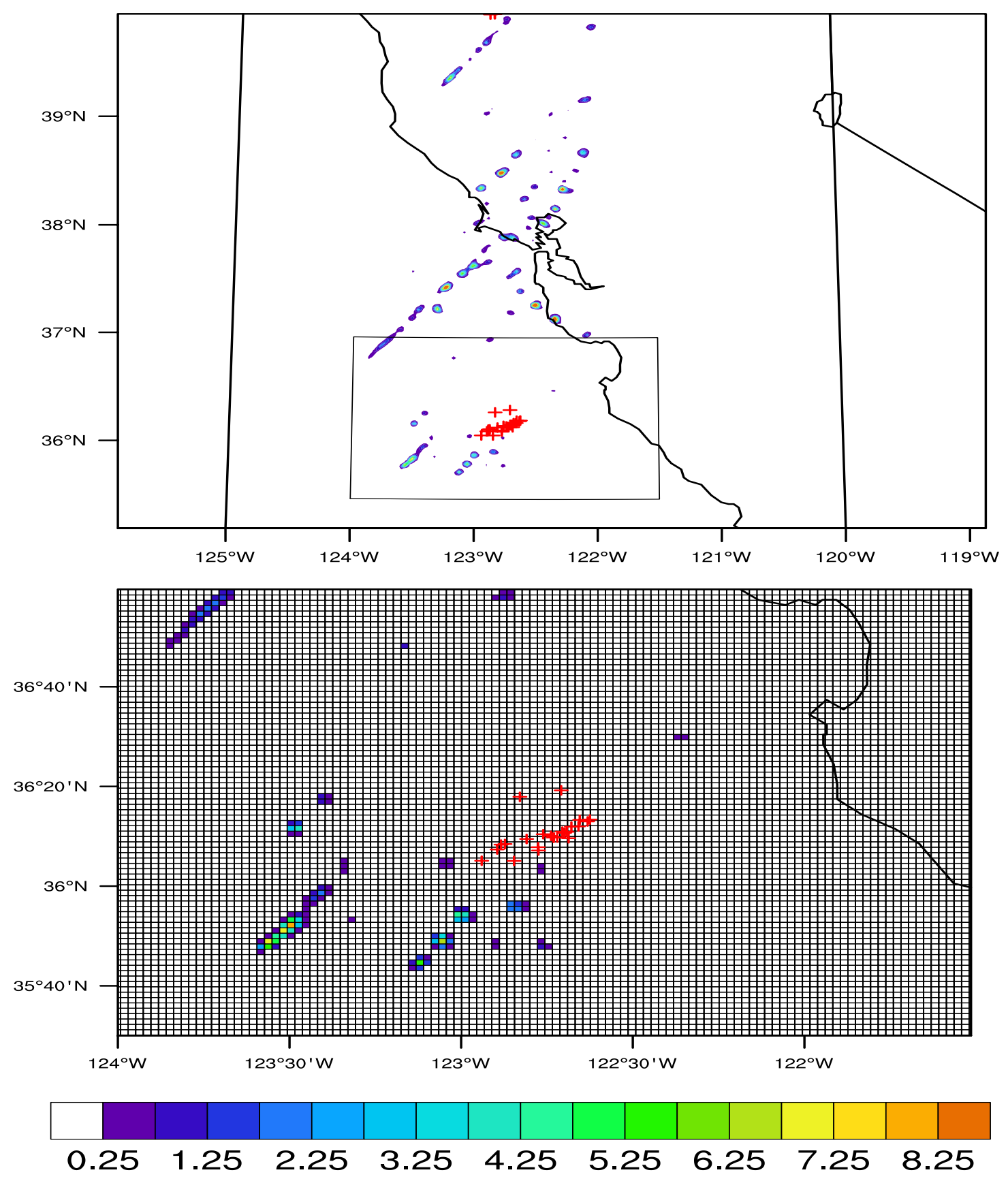

Fig. 31: Hindcast N5 simulated vertical graupel flux through the $-15^{\circ} \mathrm{C}$ isotherm (top, color fill) and zoomed in around the Monterey convective bands (bottom) to show relative size of elements in comparison to individual grid cells, valid 21 June 2008 at 1845 UTC. 


\section{Summary}

In this research, we have discussed some of the shortcomings of forecasts of the California dry lightning outbreak in 2008 . Instability generated by numerical models was focused primarily in northern California, where forecasters primarily focused their attention leading up to the event. GFS model analysis data points to ageostrophic circulations surrounding a $250 \mathrm{hPa}$ jet streak as a likely mechanism for providing the necessary lift to allow convective initiation from a plume of water vapor lofted to mid levels $(700-600 \mathrm{hPa})$. We were able to identify a tropical disturbance in the Pacific that obstructed typical easterly flow and focused it northward around high pressure over the Baja Peninsula.

High resolution WRF hindcasts had different distributions of moisture depending on when the hindcasts were initiated. The unique characteristic of the NAM hindcasts that did produce convection was the elevation of the moisture plume. In these simulations, the elevated moist layers were at least $1 \mathrm{~km}$ higher than the elevated moist layers in other hindcasts. We suggest that this higher altitude was necessary for ageostrophic circulations to lift moist parcels and take advantage of the weak instability present within the moist layer. Our other hindcasts failed to produce sufficient instability $4-6 \mathrm{~km} \mathrm{AGL}$. MUCAPE is typically analyzed in the lowest $300 \mathrm{hPa}$ of the atmosphere. Based on our work, it is our suggestion that MUCAPE calculations along the west coast consider increasing this depth to the lowest $400 \mathrm{hPa}$ to improve forecasts of elevated instability. 
Proxy variables examined from the N3 and N5 hindcasts were able to isolate areas where lightning strikes would be likely. These locations correlated well with observations, but fell short of determining the magnitude of flash rate density. The $-15^{\circ} \mathrm{C}$ isotherm is a good approximation of the mixed phase region of a storm cloud where the most riming, charged particle collisions will take place, leading to lightning. This region exists in high-based convective clouds as well as clouds closer to the surface, which is an advantage when using it to forecast dry lightning thunderstorm conditions. The calibration curve used by McCaul et al. (2009) was developed using a statistical analysis of thunderstorms primarily in the central plains and eastern states, and so, does not necessarily represent the appropriate threat of cloud electrification in storms along the west coast and more specifically, with elevated convection. Our analysis indicates that lower values (2-10 $\left.\mathrm{g} \mathrm{m} \mathrm{kg}^{-1} \mathrm{~s}^{-1}\right)$ of graupel flux are sufficient in elevated convection to electrify California storm clouds. It is possible that the effects of some other physical processes, possibly dry air entrainment, are not accounted for with this approach. However, this algorithm is still considered an invaluable post-processing tool for forecasting lightning, as it can be quickly calculated without the need to sacrifice additional computational power to embed it as a simulation-dependent variable. 


\section{Future Work}

There are some aspects to the dry lightning outbreak of 2008 that were not explored in this research. One includes analysis of the electric fields surrounding elevated storms. While the algorithm established by McCaul et al. (2009) uses a statistical approach to determine lightning threat, Lynn et al. (2012) developed an algorithm that uses a Lagrangian physics-based approach that is embedded within a simulation as a new variable to track the number of lightning discharges within the domain. This could prove useful, as non-inductive charging can occur within regions of high turbulence such as updraft/downdraft interface not just the updraft core as is assumed in McCaul et al. (2009). With this approach, numerical simulations could be employed to discover how electric charging and discharging in these storms differs from traditional surface-based convection. Either method could be used in conjunction with the dry convection probability algorithm developed by Rorig et al. (2007) to improve its high falsealarm ratio.

It would also be prudent to further explore the microphysical properties involved in cloud electrification of dry convection compared with traditional wet convection. This could be accomplished by using a double-moment microphysics parameterization in WRF to track the simulated number density of ice species. Adams-Selin et al. (2011) experimented with different values for graupel density and graupel intercept constants in the WSM6 and WDM6 microphysics schemes for a surface-based squall storm. They found that changing these constants has 
very little effect on graupel particle size distribution, but does have considerable impact on heat distribution within and surrounding the storm, and on the vertical velocity fields and of course, graupel mixing ratio. Heat distribution within storms could alter local melting and evaporation rates around graupel particles, and modulate effects of cloud electrification. This could provide another explanation as to why low values of graupel flux present in the N3 hindcast underestimated lightning threat compared with observations.

It should be noted that over the course of this research, newer versions of WRF were released that included new parameterization options to forecast lightning flash rate density. An option originally developed by Price and Rind (1994) and evaluated by Wong et al. (2013), generates lightning flash density from convective cloud top height (highest $20 \mathrm{dBZ}$ level). Their results are promising, but require domain-dependent calibration and can have mixed results at finer grid resolutions. 


\section{REFERENCES}

Adams-Selin, R. D., van den Heever, Susan C, and R. H. Johnson, 2013: Impact of graupel parameterization schemes on idealized bow echo simulations. Mon.Weather Rev., 141, 1241-1262.

Ahrens, D. C., 2012: Essentials of Meteorology: An Invitation to the Atmosphere. 6th ed. Brooks/Cole, 506 pp.

Baxter, M. A., 2011: Reforecasts of a 2004 Elevated Convection Event Misforecast by the Eta Model. National Weather Digest, 35, 3-26.

Bruning, E. C., S. A. Weiss, and K. M. Calhoun, 2014: Continuous variability in thunderstorm primary electrification and an evaluation of inverted-polarity terminology. Atmos. Res., 135, 274-284.

Corfidi, S. F., S. J. Corfidi, and D. M. Schultz, 2008: Elevated convection and castellanus: Ambiguities, significance, and questions. Weather and Forecasting, 23, 1280-1303.

Higgs, K., 2008: StatewideFireMap_062308. CAL FIRE, Accessed 17 March 2015. [Available online at http://www.fire.ca.gov/about/downloads/Statewide_Fire_Maps/StatewideFi reMap_062308.pdf]

Hirschberg, P. A., J. M. Fritsch, 1991: Tropopause undulations and the development of extratropical cyclones. Part I. Overview and observations from a cyclone event. Mon. Weather Rev., 119, 496-517.

Hirschberg, P. A., J. M. Fritsch, 1991: Tropopause undulations and the development of extratropical cyclones. Part II: Diagnostic analysis and conceptual model. Mon.Weather Rev., 119, 518-550.

Hong, S., J. J. Lim, 2006: The WRF single-moment 6-class microphysics scheme (WSM6). J.Korean Meteor.Soc, 42, 129-151.

Lackmann, G., 2011: Midlatitude Synoptic Meteorology Dynamics, Analysis, and Forecasting. American Meteorological Society, $345 \mathrm{pp}$.

Lynn, B. H., Y. Yair, C. Price, G. Kelman, and A. J. Clark, 2012: Predicting cloudto-ground and intracloud lightning in weather forecast models. Weather and Forecasting, 27, 1470-1488. 
MacGorman, D. R., W. D. Rust, T. J. Schuur, M. I. Biggerstaff, J. M. Straka, C. L. Ziegler, E. R. Mansell, E. C. Bruning, K. M. Kuhlman, and N. R. Lund, 2008: TELEX: The thunderstorm electrification and lightning experiment. Bull.Am.Meteorol.Soc., 89, 997.

McCaul Jr, E. W., S. J. Goodman, K. M. LaCasse, and D. J. Cecil, 2009: Forecasting lightning threat using cloud-resolving model simulations. Weather and Forecasting, 24, 709-729.

Moore, J. T., A. C. Czarnetzki, and P. S. Market, 1998: Heavy precipitation associated with elevated thunderstorms formed in a convectively unstable layer aloft. Meteorol.Appl., 5, 373-384.

National Weather Service, cited 2016: AHPS Precipitation Analysis. Accessed 25 February 2016. [Available at http://water.weather.gov/precip/]

Nauslar, N. J., M. L. Kaplan, J. Wallmann, and T. J. Brown, 2013: A forecast procedure for dry thunderstorms. J.Oper.Meteor, 1, 200-214.

Newman, A., R. H. Johnson, 2012: Mechanisms for precipitation enhancement in a North American monsoon upper-tropospheric trough. J.Atmos.Sci., 69, 1775-1792.

Price, C., 2009: Will a drier climate result in more lightning? Atmos.Res., 91, 479484.

Rochette, S. M., J. T. Moore, and P. S. Market, 1999: The importance of parcel choice in elevated CAPE computations. Natl.Wea.Dig, 23, 20-32.

Romps, D. M., J. T. Seeley, D. Vollaro, and J. Molinari, 2014: Climate change. Projected increase in lightning strikes in the United States due to global warming. Science, 346, 851-854, doi:10.1126/science.1259100 [doi].

Rorig, M. L., S. A. Ferguson, 1999: Characteristics of lightning and wildland fire ignition in the Pacific Northwest. J.Appl.Meteorol., 38, 1565-1575.

Rorig, M. L., S. J. McKay, S. A. Ferguson, and P. Werth, 2007: Model-generated predictions of dry thunderstorm potential. Journal of Applied Meteorology and Climatology, 46, 605-614.

Saunders, C., 2008: Charge separation mechanisms in clouds. Planetary Atmospheric Electricity, Anonymous Springer, 335-353. 
Schwartz, C. S., J. S. Kain, S. J. Weiss, M. Xue, D. R. Bright, F. Kong, K. W. Thomas, J. J. Levit, and M. C. Coniglio, 2008: Next-day convectionallowing WRF model guidance: A second look at $2 \mathrm{vs.} 4 \mathrm{~km}$ grid spacing. Proc. Preprints, 24th Conference on Severe Local Storms, Citeseer.

The NCAR Command Language (Version 6.2.1) [Software]. (2016). Boulder, Colorado: UCAR/NCAR/CISL/TDD. http://dx.doi.org/10.5065/D6WD3XH5

Unidata, (2016): Integrated Data Viewer (IDV) version 5.1 [software]. Boulder, CO: UCAR/Unidata. (http://doi.org/10.5065/D6RN35XM)

Wallmann, J., R. Milne, C. Smallcomb, and M. Mehle, 2010: Using the 21 June 2008 California lightning outbreak to improve dry lightning forecast procedures. Weather and Forecasting, 25, 1447-1462.

Wong, J., M. Barth, and D. Noone, 2013: Evaluating a lightning parameterization based on cloud-top height for mesoscale numerical model simulations. Geoscientific Model Development, 6, 429-443.

Xu, K., D. A. Randall, 1996: A semiempirical cloudiness parameterization for use in climate models. J.Atmos. Sci., 53, 3084-3102. 